\title{
The Research of Dr. Joanne Simpson: Fifty Years Investigating Hurricanes, Tropical Clouds and Cloud Systems
}

\author{
W.-K. Tao ${ }^{1}$, J. Halverson ${ }^{1,2}$, R. Adler ${ }^{1}$, M. Garstang ${ }^{3}$, R. Houze, Jr. ${ }^{4}$, M. LeMone ${ }^{5}$, \\ R. Pielke, Sr. ${ }^{6}$, and W. Woodley 7 \\ $1_{\text {Laboratory for Atmospheres }}$ \\ NASA/Goddard Space Flight Center \\ Greenbelt, MD 20771
1,2 Joint Center for Earth Systems Technology
University of Maryland, Baltimore County
Baltimore, $M D$ \\ 3 Simpson Weather Associates, Inc. \\ Charlottesville, VA. 22902 \\ ${ }^{4}$ Department of Atmospheric Sciences \\ University of Washington \\ Seattle, WA. 98195-1640 \\ $5_{N C A R}$ \\ P. O. Box 3000 \\ Boulder, CO $80307-3000$ \\ ${ }^{6}$ Colorado State University \\ Department of Atmospheric Science \\ Fort Collins, CO. 80523 \\ ${ }^{7}$ Woodley Weather Consultants \\ Littleton, CO. 80127 \\ AMS Meteorological Monographs \\ Symposium on Cloud Systems, Hurricanes and TRMM
}

(September 5, 2001)

Corresponding author address: Dr. Wei-Kuo Tao, Mesoscale Atmospheric Processes Branch, Code 912, NASA/GSFC, Greenbelt, MD 20771

email: tao@agnes.gsfc.nasa.gov 


\title{
The Research of Dr. Joanne Simpson: Fifty Years Investigating Hurricanes, Tropical Clouds and Cloud Systems
}

\author{
By \\ W.-K. Tao, J. Halverson, R. Adler, M. Garstang, R. Houze, Jr., M. LeMone, \\ R. Pielke, Sr., and W. Woodley \\ Submitted to AMS Meteorological Monographs \\ Cloud Systems, Hurricanes and TRMM
}

\section{Popular Summary}

This AMS Meteorological Monographs is dedicated to Dr. Joanne Simpson for her many pioneering research efforts in tropical meteorology during her fifty-year career. Dr. Simpson's major areas of scientific research involved the "hot tower" hypothesis and its role in hurricanes, structure and maintenance of trade winds, air-sea interaction, and observations and the mechanism for hurricanes and waterspouts. She was also a pioneer in cloud modeling with the first one-dimensional model and had the first cumulus model on a computer. She also played a major role in planning and leading observational experiments on convective cloud systems. The launch of the Tropical Rainfall Measuring Mission (TRMM) satellite, a joint U.S.-Japan project, in November of 1997 made it possible for quantitative measurements of tropical rainfall to be obtained on a continuous basis over the entire global tropics. Dr. Simpson was the TRMM Project Scientist from 1986 until its launch in 1997. Her efforts during this crucial period ensured that the mission was both well planned scientifically and well engineered as well as within budget.

In this paper, Dr. J. Simpson's nine specific accomplishments during her fifty-year career, (1) hot tower hypothesis, (2) hurricanes, (3) airflow and clouds over heated islands, (4) cloud models, (5) trade winds and their role in cumulus development, (6) air-sea interaction, (7) cloud-cloud interactions and mergers, (8) waterspouts, and (9) TRMM science, will be described and discussed 


\section{Introduction}

Dr. Joanne Simpson's major areas of scientific research involved the "hot tower" hypothesis and its role in hurricanes, structure and maintenance of trade winds, air-sea interaction, and observations and the mechanism for hurricanes and water spouts. She was also a pioneer in cloud modeling with the first one-dimensional model and had the first cumulus model on a computer. She led the work into multi-dimensional cloud modeling via observations of mergers and cloud interactions in lines. She played a major role in planning and leading observational experiments on convective cloud systems, such as the joint NOAA-Navy Project Stormfury, and the Florida Area Cumulus Experiment. She was a leading participant in the aircraft aspects of several Global Atmospheric Research Program (GARP) experiments, particularly GARP Atlantic Tropical Experiment (GATE), Monsoon Experiment (MONEX) and Tropical Oceans Global Atmosphere (TOGA) - Coupled Ocean Atmosphere Response Experiment (COARE).

Dr. Simpson's father's interest in aviation led Joanne to an interest in weather and to a meeting with Professor Rossby at the University of Chicago, which led to her beginning in meteorology. Joanne had stated "Within ten minutes I was entrained into his orbit." Later her meteorology training led to her teaching meteorology courses for aviation officers at both Chicago and NYU during the war. She was one of seven women out of 200 students in that meteorology training course and Joanne likes to note that all seven were near the top of the class. Joanne became Herbert Riehl's student at the University of Chicago focusing on the study of convective clouds. After receiving her Ph. $\mathrm{D}^{1}$ Joanne started her experimental career at Wood's Hole, moving on to NOAA, the University of Virginia and in 1979 to Goddard as head of the Severe Storms Branch and later as the project Scientist of TRMM.

Her many awards include the AMS Meisinger Award (1962), AMS Rossby Medal (1983), AMS Charles Franklin Brooks Award (1992), AMS Charles E. Anderson Award (2001), the Department of Commerce's Gold (1972) and Silver (1967) Medals and NASA's Exceptional Scientific Achievement (1982), Outstanding Leadership (1998) Medals and First William Nordberg Memorial Award for Earth Sciences (1994). Dr. Simpson was elected an AMS Fellow (1969), to the American Geographic Union (1994), an Honorary Member of the AMS (1995), an Honorary Member of the Royal Meteorological Society (1999) and to the National Academy of Engineering (1988). She has devoted herself to the AMS and served in many positions culminating in the

1 Dr. Simpson received her Ph. D. from the University of Chicago in 1949 and was the first US female to obtain a Ph. D. in Meteorology. 
Presidency of the organization. Her science partner and husband, Dr. Bob Simpson, had a major influence and was a great help to her career.

Dr. J. Simpson has made many major contributions in understanding the physical processes associated with hurricanes, tropical clouds and cloud systems in her first fifty-year career. In this paper, her nine specific accomplishments, (1) hot tower hypothesis, (2) hurricanes, (3) airflow and clouds over heated islands, (4) cloud models, (5) trade winds and their role in cumulus development, (6) air-sea interaction, (7) cloud-cloud interactions and mergers, (8) waterspouts, and (9) TRMM science, will be described and discussed.

\section{Major Research Areas and Achievements}

\section{1 "Hot Tower" hypothesis (1958 and 1979)}

Riehl and Malkus (1958) analyzed synoptic upper-air sounding data for all stations between $30^{\circ} \mathrm{S}$ and $30^{\circ} \mathrm{N}$. Specifically, they obtained temperature, humidity, and geopotential height at the 850,700 , $500,300,200,150$, and $100 \mathrm{mb}$ levels from the U. S. Weather Bureau's publication Monthly Climatic Data for the World. They used data "from 1952 onward," presumably about 5 years worth of data. The uppermost two levels were available only from 1956 onward. Riehl and Malkus obtained surface conditions from maps in the textbooks Climatology by Haurwitz and Austin (1944) and Tropical Meteorology by Riehl (1954). They considered two seasons (DecemberFebruary and June-August), and constructed mean latitude-height cross sections of the synoptic variables.

From these cross sections, they determined the mean vertical profile of moist static energy $Q$ at the location of the equatorial surface trough and at a distance of $20^{\circ}$ of latitude from the trough (Fig. 1). The decrease of $Q$ with height in the low levels, above the well-mixed layer to about 750 $\mathrm{mb}$, was previously recognized. The increase of $Q$ above $750 \mathrm{mb}$ was the focus of the paper. They proposed a hypothesis to account for the high values of $Q$ in the upper levels. They noted: "Patently, a simple mass circulation will not be able to do this, for the horizontal export to high latitudes cannot be balanced above the minimum $Q$ by a vertical advection. Radiation losses further compound the situation. We see that without some mechanism of transport other than a gradual mass circulation, the upper equatorial troposphere would be cooling at a rate of about $2^{\circ} \mathrm{C}$ per day!" 
At this point it is worth noting that Riehl and Malkus's paper contained absolutely no data on clouds and/or precipitation. Nevertheless, they postulated that clouds explained the vertical profile of $Q$. They point out that small-to-moderate entraining cumulus clouds can and probably do transport moist static energy upward to about the level of the minimum of $Q$. This fact is elegantly contained in later cumulus parameterization schemes such as those of Arakawa and Schubert (1974). Entraining cumulus do not penetrate much higher than the level of minimum $Q$. Somehow air parcels from the lowest levels of the atmosphere must be able to rise to the highest levels of the troposphere without becoming diluted by entrainment of dry environmental air. Riehl and Malkus recognized that this process must occur in "...embedded central cores in cumulonimbus clouds which are protected from mixing with the surroundings by the large cross section of the clouds." Their model for explaining the vertical profile of $Q$ in the equatorial trough zone (Fig. 2) shows the lower layer of "mixing" by entraining cumulus with "convection" consisting of "undiluted chimneys penetrating to 40,000-50,000 feet in tropical disturbances" accounting for the heat transfer to upper levels. They estimated that 1500-5000 giant clouds would maintain the observed profile of $Q$.

Riehl and Malkus's (1958) suggestion became known as the "hot tower" hypothesis. Because of the great amount of attention given to this idea, they revisited the hypothesis 21 years later (Riehl and Simpson 1979). In the second paper, the authors are not clear about how they upgraded the synoptic data set, but evidently $\sim 15$ years of additional sounding data were used. They used surface maps from the revised textbook of Riehl (1979). They alluded to satellite data, which were by then widely available, but did not include visible or infrared imagery in the paper. Using a typical size for a mesoscale convective cloud system gleaned from satellite imagery, they made otherwise similar arguments to those in the earlier paper. These arguments led them to an estimate of 1600-2400 undiluted "hot towers" (they adopted the popular terminology in this second paper), assuming a hot tower had an average area of $25 \mathrm{~km}^{2}$ and an updraft velocity of $2-3 \mathrm{~m} \mathrm{~s}^{-1}$.

It should be noted that Riehl and Malkus (1958) and Riehl and Simpson (1979) recognized that the hot towers had to be embedded in mesoscale convective systems, which were an order of magnitude greater in area than the hot tower updrafts. This awareness was based on much personal visual observation of clouds on their part (e. g. Malkus and Riehl 1964), and it foreshadowed the work on the mesoscale organization of the circulation (Zipser 1969, 1977) and precipitation (Houze 1977) in the mesoscale convective systems containing the hot towers.

\subsection{HurricanES}


Beginning in the late 1940s and into the 1950s, reconnaissance flights into tropical cyclones for operational and research purposes were collecting the first datasets documenting the inner core and rainband structure. These observations laid the foundation for Dr. Joanne Simpson's theoretical investigations into the energetics of the hurricane eye and eyewall. The first of two landmark papers was published in 1958 under the title "On the structure and maintenance of the mature hurricane eye." In this paper, significant features of the mature hurricane eye were derived in terms of a simple model of the physical processes undergone by the air composing it. These processes include detrainment of cloudy air from the tops of eyewall cumulonimbi, and the entrainment and mixing of eyewall and rain region air and angular momentum into hypothetical eye descent profiles. Resulting theoretical eye profiles computed for a moderate and an intense hurricane agreed quite closely with observed profiles. These exercises lead to the conclusion that much of the pronounced warmth of the eye occurs mainly above $700 \mathrm{mb}$, and the hydrostatic contribution to low surface pressures must come mainly from the eye column between 700 and 100 $\mathrm{mb}$. In addition, it was hypothesized that the descent leading to eye warming, which was found to be $16 \mathrm{~cm} \mathrm{~s}^{-1}$ at $850 \mathrm{mb}$, derives from low-level outflow caused by unbalanced centrifugal and Coriolis forces.

In her second significant paper, "On the dynamics and energy transformations in steadystate hurricanes" (1960), Dr. Simpson and co-author H. Riehl present a complex dynamical model of the inflow layer in a moderate, steady hurricane. The goal is to study the mechanisms by which energy release along a logarithmic spiral rainband is used to maintain the pressure field. This model relates wind speed, pressure gradient, surface shearing stress, mass flow and convergence. The ambient atmosphere can only support a 10-20 hPa drop in surface pressure. To maintain the core pressure gradient, latent heat release in the inner core region must occur at a higher heat content than the mean tropical subcloud air, and derives from enhancement of oceanic sensible and latent heat fluxes driven by increased winds. From this work emerged the important relationship $-d \mathrm{ps}_{\mathrm{s}}=2.5 \boldsymbol{\theta}_{e}$, which relates the surface pressure fall to the surface $\boldsymbol{\theta}_{e}$ of air ascending in undiluted eyewall hot towers. The importance of sensible heat fluxes is underscored by the observation that while the inflow air undergoes appreciable adiabatic expansion during its migration toward the eyewall, the temperature remains approximately constant, thus necessitating large fluxes from the oceanic heat source to make up the difference. Additional observations of the warm core in Hurricane Daisy reinforce the fact that about $75 \%$ of the surface pressure lowering derives hydrostatically from warming above $500 \mathrm{mb}$.

During the austral summer of 1993, a remarkable set of NASA instrumented aircraft flights into developing tropical cyclone Oliver captured the early formative stage of this storm, providing 
one of the very few research datasets during tropical cyclone genesis. Given the multitude of cloud clusters over tropical oceans, it is perplexing why so few develop into tropical cyclones. The complexity of scale interactions, particularly those acting on the mesoscale, may play a crucial role. In the case of Oliver, mesoscale convective systems in the preformation environment contained mesoscale convective vortices which were shown to interact and merge (Fig. 3). The interaction is essentially stochastic, but when these interactions occur in a vorticity-rich monsoon trough environment, it is shown through the use of a baroclinic model that the efficiency of mergers and the amplitude of the dominant emerging vortex is enhanced. It is hypothesized that once the vortex extended to sea surface, the increase in winds lead to enhancement of oceanic energy fluxes, thus fueling the hot towers necessary to initiate Oliver's rapid cyclogenesis. Building upon the earlier work of Ooyama (1982) and Schubert and Hack (1982), Dr. Simpson and colleagues speculate that by reducing the effective Rossby radius of deformation, the vortex merging process also facilitates confinement of latent heat to a warm core on the storm scale, rather than its diffusion away by gravity waves.

\subsection{Airflow and clouds over heated island}

Beginning with the observational study of airflow over Nantucket Island in Massachusetts (Malkus and Bunker 1952), Joanne Simpson introduced original concepts into understanding this flow. Her two-part paper (Malkus and Stern 1953a, b) applied a theoretical model to describe the airflow observed over Nantucket Island, as well as to provide a more general description of this type of mesoscale system for any flat, heated island.

In Malkus and Stern (1953b), she introduced the concept of an "equivalent mountain" which corresponds to the influence of a heated island on the airflow. The equivalent mountain effect is shown to depend only upon the temperature distribution along the surface, the wind speed, the eddy turbulent conductivity in the surface layer, and the undisturbed thermodynamic stability. Figure 4 illustrates the form of this equivalent mountain for idealized flow, while Figure 5 presents observational data for a case study day for Nantucket Island. This relation between air motion and the heating of a flat island has been confirmed repeatedly in more recent years, as illustrated, for example, in Pielke (2001a, this volume).

In Malkus (1963), the concept of the equivalent mountain was used to propose that cumulus convective rainfall could be enhanced by asphalt ground coatings. Using the small flat island of Anegada in the West Indies, she documented the generation of a cumulus cloud street by the heated island. She concluded that an asphalt coating is sufficiently promising as a way to 
promote rainfall, that it should be investigated further. This work anticipates more recent studies which have shown the major role of land-surface properties, including the net radiation received at the ground surface and the partitioning of turbulence into sensible and latent heat forms on the occurrence, intensity, and patterning of cumulus convective rainfall (Pielke 2001b).

\subsection{The Development of a Cloud Model in the Context of Cloud Seeding Experiments}

Dr. Joanne Simpson pioneered the development of a computerized, 1-dimensional, mathematical cloud model (Simpson et al. 1965) in the context of cloud seeding experiments (Simpson et al. 1967; Simpson and Wiggert 1969; 1971). These experiments in cumulus dynamics were designed to evaluate the effect of silver iodide seeding upon individual tropical cumulus clouds. The cloud model predicts the rise rate, top heights, and in-cloud properties of both seeded ad unseeded cumuli, as a function of the ambient sounding, horizontal tower dimensions, and cloud base conditions.

The initial randomized cloud seeding experiment was carried out on 23 tropical oceanic cumulus clouds on 9 days in the summer of 1965 as part of the joint Navy-ESSA Project Stormfury. Following instructions in sealed envelopes, an aircraft seeded 14 of the clouds with 8-16 pyrotechnic silver iodide generators called Alecto units. Each unit released about $1.2 \mathrm{~kg}$ of silver iodide smoke. The 9 remaining clouds were studied in an identical manner as controls, using the same stack of four instrumented aircraft to penetrate the cloud before and after the seeding run. Cloud growth was documented by aircraft, radar and photogrammetry. The seeded clouds grew vertically an average of $1.6 \mathrm{~km}$ more following the seeding run than did the control clouds; the difference is significant at the 0.01 level.

The cloud model was used to predict "seedability" and "seeding effect." Seedability is defined as the difference between the seeded and unseeded top of the same cloud. Seeding effect is defined as the difference between the observed top and the predicted unseeded top of the same cloud. Both parameters were computed and graphed for all 23 clouds. The seeded and unseeded clouds separated into two distinct populations as shown in Figure 6. Note that the seeded cases (in circles) follow closely the dashed line of perfect predictability. The correlation between observed and predicted is $0.973(\mathrm{P}<0.01)$. The unseeded cases (in boxes) obviously constitute a different population since both the means and regression slopes of the two groups differ significantly $(\mathrm{P}<$ 0.01). The unseeded cases should fall along the horizontal line (zero effect) if the physical model made perfect predictions. That is, the unseeded clouds had growth potential (seedability) that was never realized (i.e., zero seeding effect) because they were never seeded. 
This analysis shows clearly that seeding has an effect under the conditions specified and that the numerical model has considerable skill in specifying these conditions quantitatively and in predicting vertical growth for both seeded and unseeded clouds. It is the foundation upon which dynamic-mode seeding concepts have been laid, giving credibility to this approach to cloud seeding. Comparable model analyses were done for the Florida single cloud experiments (Simpson and Wiggert 1969; 1971).

Besides being of great value to dynamic-mode cloud seeding experimentation over the years, the Simpson cloud model is highly useful even today for the quantification of different largescale environments and for the testing of various convective hypotheses. It can also be used to provide dynamic and thermodynamic data sets for remote sensor algorithms.

The dynamic-mode seeding experiments were moved to Florida in 1967 and randomized seeding of individual supercooled convective clouds were conducted successfully in 1968 and 1971. Once again, statistically significant increases in cloud growth were noted following seeding along with strong indications for increased rainfall (Simpson and Woodley 1971). The Simpson 1D cloud model was refined further and applied to the new series of experiment (Simpson and Wiggert 1969; 1971). Enhanced cloud merger appeared to be a primary effect of dynamic mode seeding with greatly increased rainfall from the merged convective entities over the rainfall that would have been produced had the convective clouds remain separate.

Although Dr. Simpson formally left the Florida cloud seeding program in 1974, she continued to make important contributions to the program, trying new Bayesian statistical procedures for the analysis of seeding effects (Simpson et al. 1975), and emphasizing the importance of downdrafts as linkages in dynamic cumulus seeding effects (Simpson 1980). In the latter paper Simpson postulates that downdrafts provide the linkage between dynamically invigorated seeded cloud towers and those events below cloud base which cause enhanced inflow, new tower growth leading to cloud expansion, and frequent merger with neighboring clouds. She shows how acceleration of the cloud tops invigorated by seeding can lead to enhanced dynamic entrainment, increased evaporation, and hence to more rapidly formed and stronger downdrafts than would be the case without seeding. Evidence taken from two series of experiments on relatively isolated cumuli in the tropics and subtropics and combined with evidence derived from observational material on downdrafts collected since the late 1960's is cited to support her arguments. 
The current version of the dynamic-mode seeding experiments as articulated by Rosenfeld and Woodley (1993) and refined further since then shows the influence of Dr. Simpson over the years:

"In its present form the conceptual model involves a hypothesized series of meteorological events beginning initially on the scale of individual treated clouds or cells and cascading ultimately to the scale of clusters of clouds. This seeding is hypothesized to produce rapid glaciation of the supercooled cloud liquid water content (SLWC) in the updraft by freezing preferentially the largest drops so they can rime the rest of the cloud water into graupel. This seeding-induced graupel is postulated to grow much faster than raindrops of the same mass so that a larger fraction of the cloud water is converted into precipitation before being lost to other processes. Ice multiplication is not viewed as a significant factor until most of the cloud water has been converted into precipitation. This faster conversion of cloud water into ice precipitation enhances the release of latent heat, increases cloud buoyancy, invigorates the updraft, and acts to spur additional cloud growth and/or support the growing ice hydrometeors produced by the seeding. These processes result in increased precipitation and stronger downdrafts from the seeded cloud and increased rainfall in the unit overall through downdraft interactions between groups of seeded and non-seeded clouds, which enhance their growth and merger. 'Secondary seeding' whereby non-seeded clouds ingest ice nuclei and ice crystals produced by earlier seedings, is thought also to play a role in the precipitation enhancements." [Rosenfeld and Woodley (1993) with recent unpublished additions.]

Thus, one of the many research legacies of Dr. Joanne Simpson is the lead role that she played, both conceptually and with numerical models, in the development and testing of dynamicmode seeding concepts that are still being refined and tested today.

\subsection{Trade wind studies and the role of trade-wind cumulus in their maintenance}

Beginning in the mid-1950s (Malkus 1954, 1956, 1957, 1958; Riehl and Malkus 1957; Brier and Simpson 1969) and strongly predicated upon the pioneering field studies in the Caribbean using an instrumented aircraft, Joanne began to grapple with the fundamental energetics of the trade wind system. Were the trades driving or driven? Are the trades simply a response to high latitude forcing or are they being maintained by processes embedded within this limb of the general circulation? What was the basis for the observed remarkable steady state nature of the trade winds? And, how does one account for the paradox that the atmosphere's most violent vortex, the hurricane, occurs intermittently within this steady state system? 
Remarkably in these studies, Joanne not only perceived that the system was highly scaledependent but she was able to link these disparate scales into a coherent whole. While we are still grappling with the question of how fluxes of heat, moisture and momentum across the tropical ocean interface are directly coupled to the convective and larger scales of the deeper atmosphere, Joanne quickly established the crucial role played by both shallow and deep cumulus clouds in the tropical atmosphere.

In her 1954 paper, Joanne established from aircraft penetrations of cumulus clouds, the basic processes of entrainment (and detrainment). The trade wind cumuli act to elevate moisture along the trajectory, progressively heightening the trade wind inversion. She also began, in this paper, formulating early thoughts on cloud models and cloud mergers.

By 1956, Joanne had produced a simplified model of the trade winds which incorporated cloud-produced diabatic heating. The model simulated most of the important features of the trades such as subsidence, downstream acceleration, increased vertical shear of the horizontal wind and a downstream pressure drop (Fig. 7). Agreement between the motion and pressure fields depended upon the introduction of frictional stresses. The scale-dependent nature of the system is illustrated by the interplay between large-scale subsidence which suppresses convection and convective growth which, if enhanced, would trigger greater subsidence. The balance which is struck between these two scales results in the observed steady state of the trades.

Work completed in 1957 and 1958 (Riehl and Malkus 1957; Malkus 1958) shows that the trades export through the circuitous route of deep convection in the equatorial trough, sensible and latent heat to higher latitudes. The sensible heat gain is related to the surface pressure distribution and the trades are found to be a self-driving system.

Joanne grappled throughout her career with how, in this steady state system, regions of deep clouds and rainfall formed which were the necessary but not sufficient conditions for hurricane formation. In her work with Glenn Brier (1969), she demonstrated the sensitivity of the tropical atmosphere to small but periodic changes in the fields of divergence. In an earlier study (Simpson et al. 1967) she had shown that meso- to synoptic-scale systems in the tropics can occur without any detectable perturbation of the horizontal velocity field. Classical wave or vortex structures in the velocity field were not a necessary condition for the development or organized deep convection. 
In these and other studies Joanne has pointed to the need to adequately describe the threeor even two-dimensional velocity and moisture fields of the tropics. These two variables, velocity and moisture, remain the keys to unlocking the remaining puzzles of the tropical atmosphere.

\subsection{Air-Sea Interaction}

Joanne Simpson's work has always portrayed air-sea interaction not as an isolated process, but as a piece of a complex, interacting system. Her understanding and enthusiasm were fueled by association with Woods Hole, which in the 1940 s and 1950 s did repeated measurements in the Caribbean using both ships and one of the first instrumented aircraft (Bunker 1955). This view has elucidated the role of sea-air interaction in the larger context of weather and climate, and provided estimates of the flux interchange at the interface from both budgets and bulk aerodynamic techniques. Such cross-checks free the reader from excessive worry about the accuracy of the exchange coefficients in the bulk aerodynamic formulas used to predict air-sea fluxes, which continues to be an area of active research. Her work has spanned phenomena from the global circulations that serve as context to her work on the trade wind and equatorial trough zones, to the disturbances, hurricanes and extratropical cyclones that modulate and feed off energy from the sea surface, to the smallest eddies transporting heat, moisture and momentum from the sea surface and the clouds carrying the energy high into the troposphere. As will be seen in this section, the role of the sea-air exchange varies with the context.

Simpson's (1969) paper on the role of sea-air interaction in the development of mid-latitude cyclones illustrates her holistic approach. Treatment of this subject had led to mixed conclusions; Simpson's synthesis of the known work at the time explored the reasons for these conclusions, drawing from her experience with convection in the tropics. She began with the Petterssen et al. (1962) composite of a developing cyclone, and showed the well-known concentration of strong fluxes in the unstable air (cold air over warm water) behind the cold front. Applying her experience with cloud development in the tropics (Malkus and Ronne 1960), Simpson quickly arrived at the essential point, that it is not the fluxes themselves, but whether the fluxes occurred under conditions that favored deep penetrative convection that can heat the atmosphere through a deep layer, that determined whether or not the fluxes contributed to cyclone deepening. She used the well-known study of Winston (1955) as an example of rapid cyclone deepening from fluxes and penetrative convection under favorable synoptic conditions (positive vorticity and vertical velocity); the Winston case at later times and a storm documented by Bunker (1957) provided counter-examples, with strong surface fluxes having little effect because of strong low-level inversions. The Petterssen $e t$ al. (1962) composite provided an intermediate example, with some areas of deep convection over 
the strong fluxes, but only a small effect apparently because precipitation (latent heating) was small. Early numerical simulations of developing marine extratropical cyclones at GFDL indicated that inclusion of surface fluxes improved forecasts (e.g., Miyakoda et al. 1969), especially when seasurface temperature anomalies were included (J. Simpson discussion with Miyakoda).

The 1969 synthesis has been refined but not changed in essence by high resolution numerical simulations and focused field programs such as the ERICA (Experiment on Rapidly Intensifying Cyclones over the Atlantic) field experiment, which was held over the North Atlantic from December 1, 1988 - February 28, 1989 (Hadlock and Kreitzberg 1988). The importance of latent heat release in rapid cyclogenesis was demonstrated in a number of numerical experiments (e.g., Anthes et al. 1983, Kuo and Reed 1988) and confirmed for a number of ERICA storms (e.g., Reed et al. 1993, Rausch and Smith 1996). Air joining such cyclones may have already been moisture-enriched well away from the storm, but well-placed locally-enhanced fluxes have been shown to play a role in the intensification of some storms (Reed et al. 1993, Wakimoto et al. 1995). However, current papers focus on flux-enriched air being available for slantwise as well as vertical convection (e.g., Reuter and Yau 1993).

Simpson is well known for her important work done on the role of air-sea exchange in the trades, drawing from measurements over both the Atlantic (e.g., Woods Hole expeditions described in Woodcock and Wyman 1947, Bunker et al. 1949, Malkus 1958b, Colon 1960) and Pacific (Riehl et al. 1951, Riehl and Malkus 1957). As in the review paper on extratropical cyclogenesis, Simpson's article in The Sea quickly emphasized that large surface energy fluxes do not lead to convection in the presence of a capping inversion - in this case, the trade-wind inversion ${ }^{2}$. Rather, the trade inversion contains the moistening air until it reaches the equatorial trough zone, where more favorable thermal stratification and convergence allows the air to rise in deep convective "hot towers" that heat the middle and upper troposphere in the equatorial trough zone. Riehl et al. (1951) and Colon (1960) found the surface latent and sensible heat fluxes as residuals in the energy budgets that are consistent with bulk formulas and current estimates. Riehl and Malkus (1957) showed that the along-stream pressure gradient in the Pacific trades could be accounted for by the observed heating. From the budgets in Riehl et al. (1951), the streamwise pressure gradient is, to close approximation, also related to the vertical divergence of momentum transport. Combined, these two relationships link the sensible heat flux and streamwise surface stress, which to good approximation, is the total. By allowing the streamwise velocity to accelerate, combining

2 While the modulation of deep convection by easterly waves in GATE is consistent with this finding, the modulation of convection by larger-scale motions in the Pacific warm pool during TOGA COARE was not so clear (e.g., Raymond 1995). 
the kinematic equations, the gas law, and the first law of thermodynamics, under the above approximations, Simpson (Malkus 1956) showed how heating, a streamwise pressure drop, and subsidence are related in the trade wind zone, and predicted the often-observed wind maximum at cloud base.

Simpson and colleagues pioneered in studies of the heat and moisture flux through the subcloud and cloud layers of the trade wind zone. The work was mainly based on the previouslymentioned series of Woods Hole expeditions to the Caribbean. Simpson's classic work (Malkus 1958b) describes the structure and processes in the subcloud (divided into a well-mixed layer and transition layer) and cloud layers (Fig. 8). The Woods Hole group correctly deduced that the sensible-heating profile in the subcloud layer goes negative at a surprisingly low level, typically about one-third of the way to cloud base $(\sim 200 \mathrm{~m})$ based on aircraft data (Bunker 1956, Fig. 53, Malkus 1962). This deduction was supported by Colon's (1960) budget for the Caribbean Basin (Malkus 1962, Fig. 30), although the ratio of downward heat flux near the top of the mixed layer to that at the surface is slightly larger than generally observed. Similarly, the ratio of latent-heat flux near cloud top to that at the surface, about 0.8 , is within the range of values from later studies $(0.75$ 0.85) obtained by Riehl et al. (1951), Augstein et al. (1973), and Esbensen (1975). To determine whether the budget-based humidity transport within the cloud layer was reasonable, Simpson (Malkus 1962) subdivided the trade cumulus layer into active and descending cloud material, and environmental air and used observation-based cloud fraction, active cloud fraction, temperature, and environmental subsidence in the mass-continuity and flux equations. She found that, under the additional assumption (based on observational experience) of about $6 \%$ of the cloud being active and the remainder subsiding at a small speed (order $0.1 \mathrm{~ms}^{-1}$ ), the observed water-vapor fluxes were consistent with active-cloud updrafts of $2 \mathrm{~ms}^{-1}$, which is consistent with observations in Malkus (1954) and elsewhere.

Using smoke plumes, shipboard data, aircraft data, and reasoning based on budgets, Simpson (Malkus 1962) provided an early glimpse of how heat, vapor, and momentum are transported through the mixed layer. The ship data showed the expected association of low momentum with warm, moist air rising from the sea surface. She recognized that moisture, as well as temperature contributes to the buoyancy of rising thermals (Malkus 1962, p. 207), a finding that even today catches the uninitiated by surprise. However, the lack of fast humidity measurements on the Woods Hole aircraft in 1958 (Fig. 53, Malkus 1962) precluded a detailed look at thermals. Once they reached high enough altitudes, it was not possible to determine that their buoyancy was mainly due to water vapor. It was not until the 1960s that fast humidity measurements (e.g., Telford and Warner 1964) afforded the opportunity to trace water-vapor-induced buoyancy in plumes or 
bubbles through the mixed layer, and these two authors focused their attention on thermals over land, where temperature-induced buoyancy is relatively more important. Equipped with fast humidity measurements (Lenschow 1984) and inspired by the earlier Woods Hole efforts, LeMone and Pennell (1976) were able to connect cloud streets north of Puerto Rico to the sea surface by finding cloud source regions in the form of high-virtual temperature upwelling regions of horizontal roll vortices, whose buoyancy was entirely due to water vapor in the upper two-thirds of the subcloud layer. The roll upwelling regions were basically broad areas that favored the rise of thermals from the sea (Figure 9). Directly linking clouds to the ocean surface via cloud-scale "roots" is more difficult. Lenschow and Stephens (1980) showed that convective thermals over the warm waters of the South China Sea ${ }^{3}$, identified by positive mixing ratio fluctuations, followed a coherent pattern through the subcloud layer, becoming steadily larger (diameter $d \sim z^{l / 3}$ ) and widely spaced (number $N \sim z^{-1 / 3}$ ) with height $z$. Tying the thermals directly to clouds has proved more difficult. LeMone and Pennell (1976) were able to trace cloud-scale buoyant updrafts to about 100 $\mathrm{m}$ below cloud base in a regime with deeper trade wind cumulus; they argued the roots at lower altitudes, if present at all, could lie outside the aircraft track. Based on tethered balloon data, Garstang (Garstang and Fitzjarrald 1998) argued that the roots of growing cumulus extend downward as the clouds develop, presumably as a result of cloud-related low pressure (LeMone $e t$ al. 1988a,b).

Although Simpson's considerable contributions to the understanding of hurricanes are summarized elsewhere, we briefly summarize her role (Malkus and Riehl 1960, Riehl and Malkus 1961 ), in defining how the heating and frictional drag worked in the inner core (less than $\sim 100 \mathrm{~km}$ from the center) of a moderate hurricane. By the time these papers were written, it was recognized (Byers 1944, Riehl 1954) that surface heating was necessary to lower pressure enough to make a hurricane. The model that grew out of the Malkus-Riehl collaboration is summarized in Malkus (1962). Assuming a symmetric pressure field, a constant drag coefficient and inflow depth and inflow winds independent of height, they obtained a wind field (and therefore stress field) that was reasonably consistent with observations and bulk aerodynamic estimates. The model results were then combined with thermodynamic data from Daisy (1958) and an amazingly astute assumption of constant sea-air temperature contrast to derive a heat-energy budget that yielded surface latent and sensible heat fluxes as a residual. These fluxes agreed with bulk-aerodynamic measurements to within 20 per cent. A refined budget using actual wind measurements in Daisy and a smaller sea-air

3 While it can be argued that this environment is fundamentally different from the trades, the temperature in the thermals behaves similarly to those in the trades, becoming lower than the environment about half-way up the subcloud layer. 
temperature contrast, yielded flux values and a Bowen ratio (0.2) that matches values in similar hurricanes (Riehl and Malkus 1961, Cione et al. 2000).

This basic outline holds today, but enriched by details. Careful analysis of air-sea temperature contrast on average upholds the assumption of a near-constant air-sea temperature difference in the hurricane's inner core (Cione et al. 2000). More recent research focuses on what produces the air-sea temperature difference. Although it has been clear for several years that the sea surface temperature is cooled by wind-induced mixing with cooler waters below (e.g., Malkus 1962, p.111), it is now recognized (Emanuel 1999) that the temperature stratification in the upper ocean in the hurricane's path can have a significant effect on the sea surface temperature, and thereby surface fluxes and hurricane development. Similarly, hurricane researchers are looking more closely at the processes that affect the inflow temperature, such as intrusion of penetrative downdrafts from precipitating convection (e.g., Emanuel 1995, Cione et al. 2000), which bring low $\theta_{e}$ air into the boundary layer, and entrainment (Barnes et al. 1995), whose effect depends on the air above the inflow layer. At larger distances (>150 km) from the hurricane center, Cione et al. (2000) found that $\theta_{e}$ actually drops as air converges inward. The values of the exchange coefficients relating air-sea temperature, specific humidity, and wind differences to the corresponding fluxes and the potential effect of sea spray remain tantalizing unknowns, but Simpson and Riehl's work suggests that the early surface flux estimates weren't far off.

Simpson's work since this era (summarized elsewhere in this paper) has expanded to include numerical modeling but still involves the "expense and labor" needed to analyze the model results. A recent focus, along with colleagues (Wang et al. 1996, 2001) uses the Goddard Cumulus Ensemble (GCE) model to ascertain the role of air-sea fluxes in the development of mesoscale convective systems. As in the case of extratropical cyclones and the trade wind region, whether the fluxes have an impact has as much to do with whether they can feed clouds that penetrate into the upper troposphere. Results indicate that the significantly enhanced fluxes beneath the convection affect system development and precipitation amount far less than the transports in the environmental air that eventually forms the deep convection.

\subsection{Cloud-Cloud Interactions and Mergers}

It has been recognized that the largest and most persistent convective clouds are often formed by the merging of two or more adjacent cells. Over the years, Dr. J. Simpson developed an original idea that showed how clouds merged into organized convective complexes that are the major producers of rainfall in the tropic (Malkus 1954; Malkus and Riehl 1964; Simpson et al. 1980, 1993). 
Conventional digitized radar employed during the Florida Area Cumulus Experiment (FACE, 19701976) and GARP Atlantic Tropical Experiment (GATE, 1974) presented a unique, first opportunity to identify as well as quantify the importance of the growth of cumulus showers by cloud-cloud interaction and merging. In Simpson et al. (1980), a merger is defined as the consolidation of two previously separate echoes at the $1 \mathrm{~mm} \mathrm{hr}^{-1}$ isopleth of rain rate. A first-order merger is the result of the joining of two or more previously independent single echoes, and a second-order merger is formed by the juncture of two or more first or second-order mergers. She and her colleagues found that the second-order mergers contributed about $68 \%$ of the rainfall and accounted for 53\% the area covered by echo. Single echoes and the first-order mergers contributed similar properties of rainfall and total area. However, of all the echoes, nearly $90 \%$ were un-merged and only about $10 \%$ merged. In Florida, on relatively undisturbed days, Dr. Simpson found that mergers of showers occurred predominantly in seabreeze convergence zones, based on their predicted locations by a mesoscale model.

Simpson et al. (1993) studied a family of very tall (up to $20 \mathrm{~km}$ ) cumulonimbus complexes that developed almost daily over an adjacent pair of flat islands in the Maritime Continent region north of Darwin, Australia, known locally as "Hectors". About $90 \%$ of the total rainfall came from these merged systems which comprised less than $10 \%$ of the convective systems. It was found that the trend for the Hector and Florida storms was consistent and implied that total rainfall production comes from a multiplicative enhancement of production by cloud-scale interaction. Using rawinsonde and surface observations (including radiation and soil measurements), Dr. Simpson found that approximately $15 \%$ of the moisture source for the rainfall was provided by evapotranspiration, $45 \%$ by the sea-breeze convergence of warm, moist oceanic air, and $40 \%$ by "mining" of the original island boundary layer once the precipitation began.

Simpson et al. (1980) postulated that downdraft or gust front interaction is the primary mechanism of shower mergers. The approach or collision of gust fronts/downdrafts from adjacent clouds can force warm moist air upward which in tropical air masses is both conditionally and convectively unstable. Her colleagues, Ulanski and Garstang (1978) found that stronger gust fronts were associated with moving, in contrast to stationary, showers. With wind shear, the merger processes should be different and more effective in joining and organizing cloud systems. Another important finding by Dr. Simpson was that the merging of convective showers is usually proceeded by a "bridge" of visible smaller cumuli. The occurrence of the cloud-bridge may simply manifest the importance of low-level convergence to the merging process. Dr. Simpson's proposed cloudcloud interactions and merging mechanism is shown schematically in Fig. 10. 
Using a three-dimensional cloud model to study cloud-cloud interactions and mergers, Tao and Simpson (1989) found that the primary initiating mechanism for the occurrence of a secondorder merger is the low-level convergence associated with cold cumulus outflows. [See Tao (2001) for a review and discussion of other possible mechanisms associated with first-order mergers.]

\section{$2.8 \quad$ Waterspouts}

Starting back in the mid-1980's, Dr. Simpson and colleagues undertook research into the enigmatic origins of waterspouts. Two key published papers emerged (Simpson et al. 1986 and 1991) which focussed on waterspouts during GATE and over the Great Salt Lake. Building upon intensive observations published by Golden in the 60's and 70's, Dr. Simpson's approach was to combine conventional data (i.e., soundings, surface data, satellite imagery and photography) with cloudresolving numerical models in order to elucidate the mechanisms for waterspout formation and dissipation.

In their GATE paper, Simpson et al. (1986) hypothesize the necessity of parent vortices originating in the form of a cumulus-scale vortex pair. The vertical pair results from the tilting of ambient horizontal shear vorticity in the cloud environment. An active updraft intensifies the vortices below cloud base, with the relatively short lifetime of the waterspout coupled to the short duration of active updrafts within a growing congestus cloud. The three-dimensional numerical model of Schlesinger was used to simulate two cases of congestus growth based on observations collected from two days in GATE. In the one case featuring weak instability and low-level shear, the updraft was undercut early by a downdraft and a vortex pair could not be extended to the surface. In the other, a more unstable subcloud layer was prescribed along with strong low-level shear, which resulted in strong parent vortices with maximum intensity at the surface. An unstable lower cloud layer appears to be a necessary but insufficient condition; given a favorable thermal environment, differences in the low-level wind profile are clearly crucial. It is noted that during both of the GATE case study days, waterspout formation was noted in the area where two gust fronts approached one another. Given a cumulus-scale parent vortex, the gust front interaction may provide the final convergence needed to stretch and amplify the subcloud vortex to waterspout strength. The mechanism is shown schematically in Fig. 11.

In the Great Salt Lake paper, Simpson et al. (1991), detailed analyses of a waterspout that formed in a cumulus line over the lake are presented. The spout was anticyclonic and formed in an environment of strong low-level instability and shear. A series of numerical experiments were undertaken using the Goddard-Schlesinger cloud model. The model work capitalizes on several 
modifications made since the earlier (1986) waterspout work, including the introduction of icephase processes and an embedded high-resolution axisymmetric vortex model. Cloud forcing was undertaken using both a convergence line-type initiation and also a buoyant bubble. Both types resulted in formation of a cloud-scale vortex pair, but the line initiation developed stronger vortices, especially the anticyclonic member. An important finding is that the model cloud processes alone (i.e., pre-existing anticyclonic rotation in the parent cloud) can produce a waterspout in the absence of external vorticity sources.

It should be noted that today additional ideas have emerged regarding the exact mechanism responsible for formation of non-violent tornadic vortices (i.e., waterspouts and landspouts) namely, Simpson's theory of pre-existing organized vorticity contained within the cumulus cloud, and that of Wakimoto and Wilson (1989) as prescribed for non-supercell tornado/landspout development. According to the Wakimoto and Wilson study, the rotation originates from low-level horizontal shear initially unrelated to (external to) overhead cloud processes, which then becomes stretched upward when it coincides with a convective updraft. As noted by Simpson et al. (1991), it is likely that in the case of waterspouts, both mechanisms may be important, in varying degrees depending on the cloud environment.

\subsection{Tropical Rainfall Measuring Mission (TRMM) Science}

Joanne became Project Scientist for the fledgling Tropical Rainfall Measuring Mission (TRMM) in 1986. She brought to TRMM her forty years or so of study and research in tropical meteorology and a particular knowledge of convective systems and storms in that region. She also had a very strong interest in using TRMM to answer questions related to tropical precipitating systems and their impact on climate processes. In this TRMM role, she led the development of the TRMM Science Goals and the observational requirements necessary to achieve them. This work was described in a ninety page TRMM science document by her and the initial TRMM Science Steering Group. Joanne also took the step at this early stage of TRMM to condense this scientific rationale for TRMM into an article for the Bulletin of the American Meteorological Society (AMS) (Simpson et al. 1988), complete with a cover image showing an artist's conception of the TRMM spacecraft. This early broad exposure of the TRMM concept, and the scientific basis for it, was accomplished more than nine years before the TRMM launch.

In the years leading up to the TRMM launch, Joanne continued her research focusing on convective systems using observations and models. In this pre-TRMM period, she resumed her use of field experiment data, including that from the ARMAR aircraft radar, a simulator for the 
Precipitation Radar (PR) on TRMM. This field work culminated in a review of tropical cyclone formation emphasizing the role of "hot towers" in early intensification of systems (Simpson et al. 1998). By using the aircraft radar data and electrification and lightning information in these studies, she was preparing for the use of TRMM data in tropical cyclone studies. In addition, she also contributed to algorithm research directly related to the TRMM mission in the area of satellite microwave observation of precipitation (Adler et al. 1991) and retrieval of latent heat profiles using models and satellite data (Tao et al. 1993).

With the successful launch of TRMM in late 1997, Joanne stepped down as TRMM Project Scientist and focused on TRMM-based tropical cyclone research, but also published a summary of early mission results (Simpson et al. 2000). Initial, exciting results of the TRMM views of Typhoon Paka (Simpson et al. 1998) gave an early indication of the importance of TRMM data in diagnosing convective bursts, showing a very tall TRMM radar echo (see Fig. 12). Joanne and colleagues are continuing to study TRMM data to understand the relations of these features, noted in numerous cases, to cyclone strength and intensification.

\section{References}

Adler, R. F., H.-Y. M. Yeh, N. Prasad, W.-K. Tao, and J. Simpson, 1991: Microwave simulations of a tropical rainfall system with a three-dimensional cloud model. J. Appl. Meteor., 30, 924-953.

Anthes, R. A., 1983: Regional models of the atmosphere in middle latitudes. Mon. Wea. Rev., 111, 1306-1335.

Arakawa, A., and W. H. Schubert, 1974: Interaction of a cumulus ensemble with the large-scale environment: Part I. J. Atmos. Sci., 31, 674-701.

Augstein, E., H. Riehl, R. Ostapoff, and V. Wagner, 1973: Mass and energy ttransports in an undisturbed Atlantic trade-wind flow. Mon. Wea. Rev., 101, 101-111.

Barnes, G. M., and M. D. Powell, 1995: Evolution of the inflow boundary layer of hurricane Gilbert (1988). Mon. Wea. Rev., 123, 2348-2368.

Brier, G. W., and J. Simpson, 1969: Tropical cloudiness and rainfall related to pressure and tidal variations. Quart. J. Roy. Meteor. Soc., 95, 120-147. 
Bunker, A. F., B. Haurwitz, J. S. Malkus, and H. Stommel, 1949: Vertical distribution of temperature and humidity over the Caribbean Sea. Papers Phys. Oceanog. Met., Mass. Inst. Tech. And Woods Hole Oceanog. Inst., 11, 82pp.

Bunker, A. F., 1955: Turbulence and shearing stresses measured over the North Atlantic Ocean by an airplane acceleration technique. J. Meteor., 12, 445-455.

Bunker, A. F., 1956: Measurements of counter-gradient heat flows in the atmosphere. Austral. J. Phys., 9, 133-143.

Bunker, A. F., 1957: Turbulence measurements in a young cyclone over the ocean. Bull. Amer. Meteor. Soc., 38, 13-16.

Byers, H. R., 1944: General Meteorology. McGraw-Hill, New York.

Cione, J. J., P. G. Black, and S. H. Houston, 2000: Surface observations in the hurricane environment. Mon. Wea. Rev., 128, 1550-1561.

Colon, J., 1960: On the heat balance of the troposphere and water body of the Caribbean Sea. National Hurricane Res. Project, Report No. 41, U.S. Dept. of Commerce, Washington, D.C., $65 \mathrm{pp}$.

Emanuel, K., 1995: Sensitivity of tropical cyclones to surface exchange coefficients and a revised steady-state model incorporating eye dynamics. J. Atmos. Sci., 52, 3969-3976.

Esbensen, S., 1975: An analysis of subcloud-layer heat and moisture budgets in the western Atlantic trades. J. Atmos. Sci., 32, 1921-1933.

Garstang, M., and D. R. Fitzjarrald, 1998: Observations of Surface to Atmosphere Interactions in the Tropics. Oxford Univ. Press, $384 \mathrm{pp}$.

Hadlock, R., and C. W. Kreitzberg, 1988: Experiment on Rapidly Intensifying cyclones over the Atlantic (ERICA): Field study, objectives, and plans. Bull. Amer. Meteor. Soc., 69, 1309-1320.

Haurwitz, B., and J. Austin, 1944: Climatology. McGraw Hill, New York, 410 pp. 
Houze, R. A., Jr., 1977: Structure and dynamics of a tropical squall-line system. Mon. Wea. Rev., 105, 1540-1567.

Kondo, J., 1975: Air-Sea Bulk Transfer Coefficients in Diabatic conditions. Boundary-Layer Meteor., 9, 91-112.

Kuo, Y.-H., and R. J. Reed, 1988: Numerical simulations of an explosively-deepening cyclone in the eastern Pacific. Mon. Wea. Rev., 116, 2081-2105.

LeMone, M. A., and W. T. Pennell, 1976: The relationship of trade-wind cumulus distribution to subcloud-layer fluxes and structure. Mon. Wea. Rev., 104, 524-539.

LeMone, M. A., G. M. Barnes, J. C. Fankhauser, and L. Tarleton, 1988a: Pressure fields measured by aircraft around the cloud-base updraft of deep convective clouds. Mon. Wea. Rev., 116, 313-337.

LeMone, M. A., L. F. Tarleton, and G. M. Barnes, 1988b: Perturbation pressure at the cloud base of cumulus clouds in low shear. Mon. Wea. Rev., 116, 2062-2068.

Lenschow, D. H., 1984: Aircraft measurements in the boundary layer. In Probing the Atmospheric Boundary Layer, p. 39-55. D.H. Lenschow, Ed. American Meteor. Soc., 269 pp.

Lenschow, D. and P. L. Stephens, 1980: The role of thermals in the convective boundary layer. Bound.-Layer Meteor., 19, 509-532..

Malkus, J. S. and A. Bunker, 1952: Observational studies of the air flow over Nantucket Island during the summer of 1950. Pap. Phys. Oceanogr. Meteor., 12, 50 pp.

Malkus, J. S., and M. E. Stern, 1953a: The flow of a stable atmosphere over a heated island. Part I. J. Meteor., 10, 30-41.

Malkus, J. S., and M. E. Stern, 1953b: The flow of a stable atmosphere over a heated island. Part II. J. Meteor., 10, 105-120.

Malkus, J. S., 1954: Some results of a trade-cumulus cloud investigation. J. Meteor., 11, 220-237. 
Malkus, J. S., 1956: On the maintenance of the trade winds. Tellus, 8, 335-350.

Malkus, J. S., 1957: Trade cumulus cloud groups: Some observations suggesting a mechanism of their origin. Tellus, 9, 33-44.

Malkus, J. S., 1958a: On the structure and maintenance of the mature hurricane eye. J. of Meteor., $4,337-349$.

Malkus, J. S., 1958b: On the structure of the trade wind moist layer. Papers in Phys. Oceanog. and Meteor., 13, 3-47.

Malkus, J. S., and H. Riehl, 1960: On the dynamics and energy transformations in steady-state hurricanes. Tellus, 112, 1-20.

Malkus, J. S., and C. Ronne, 1960: Cloud distributions over the tropical oceans in relation to largescale flow patterns. Physics of Precipitation. Proc. Cloud Phys. Conf. Woods Hole, Mass., 1950. Geopohys. Monograph Series, Amer. Geophys. Union Publication 746, Waverly Press, Baltimore, 45-60.

Malkus, J. S., 1962: Large scale interactions. The Sea: Ideas and Observations on Progress in the Study of the Seas. Chapter 4, v. 1, 88-294. Interscience Publishers, New York and London.

Malkus, J. S., 1963: Tropical rain induces by a small natural heat source. J. Appl. Meteor., 2, 547556.

Malkus, J. S., and H. Riehl, 1964: Cloud Structure and Distributions over the Tropical Pacific Ocean. Univ. Calif. Press, Berkeley, 229 pp.

Miyakoda, K., J. Smagorinsky, R. F. Strickler, and G. D. Hembree, 1969: Experimental extended predictions with a nine-level hemispheric model. Mon. Wea. Rev., 91, 1-76.

Ooyama, K. V., 1982: Conceptual evolution of the theory and modeling of the tropical cyclone. $J$. Meteor. Soc. Of Japan, 60, 369-380.

Petterssen, S., D. L. Bradbury, and K. Pedersen, 1962: The Norwegian cyclone models in relation to heat and cold sources. Geofys. Publn., 24, 243-280. 
Pielke, R. A., Sr., 2001a: The Experimental Meteorology Laboratory (EML) and University of Virginia Years with Joanne Simpson -- An ideal model of mentorship. Meteor. Monograph., (this issue).

Pielke, R. A., Sr., 2001b: Influence of the spatial distribution of vegetation and soils on the prediction of cumulus convective rainfall. Rev. Geophys., 39, 151-177.

Rausch, R. L., and P. J. Smith, 1996: A diagnosis of a model-simulated explosively developing extratropical cyclone. Mon. Wea. Rev., 125, 875-904.

Raymond, D., 1995: Regulation of moist convection over the west Pacific warm pool, J. Atmos. Sci., 52, 3945-3959.

Reed, R. J., G. A. Grell, and Y.-H. Kuo, 1993: The ERICA IOP5 storm. Part II: Sensitivity tests and further diagnosis based on model output. Mon. Wea. Rev., 121, 1595-1612.

Reuter, G. W., and M. K. Yau, 1993: Assessment of slantwise convection in ERICA cyclones. Mon. Wea. Rev., 121, 375-386.

Riehl, H., T. C. Yeh, J. S. Malkus, and N. E. LaSeur, 1951: The norh-east trade of the Pacific Ocean. Q. J. Roy. Meteor. Soc., 77, 598--626.

Riehl, H., 1954: Tropical Meteorology. McGraw-Hill, New York, 392 pp.

Riehl, H., and J. S. Malkus, 1957: On the heat balance and maintenance of circulation in the trades. Quart. J. Roy. Meteor. Soc., 83, 21-29.

Riehl, H., and J. S. Malkus, 1958: On the heat balance in the equatorial trough zone. Geophysica, 6, 503-538.

Riehl, H., and J. S. Malkus, 1961: Some aspects of Hurricane Daisy, 1958. Tellus, 8, 181-213.

Riehl, H., 1979: Climate and Weather in the Tropics. Academic Press, New York, 611 pp. 
Riehl, H., and J. S. Simpson, 1979: The heat balance of the equatorial trough zone, revisited. Contrib. Atmos. Physics, 52, 287-305.

Rosenfeld, D., and W. L. Woodley, 1993: Effects of cloud seeding in west Texas: Additional results and new insights. J. Appl. Meteor., 32, 1848-1866.

Schubert, W. H., and J. J. Hack, 1982: Inertial stability and tropical cyclone development. J. Atmos. Sci., 39, 1688-1697.

Simpson, J., R. H. Simpson, D. A. Andrews, and M. A. Eaton, 1965: Experimental cumulus dynamics. Reviews of Geophysics, 3, 387-431.

Simpson, J., G. W. Brier and R. H. Simpson, 1967: Stormfury cumulus seeding experiment 1965: Statistical analysis and main results. J. Atmos. Sci., 24, 508-521.

Simpson, J., M. Garstang, E. J. Zipser, and G. A. Dean, 1967: A study of a non-deepening tropical disturbance. J. Appl. Meteor., 6, 237-254.

Simpson, J., 1969: On some aspects of sea-air interaction in middle latitudes. Deep Sea Research, F24, v. 16, Pergamon Press, 233-261.

Simpson, J., and V. Wiggert, 1969: Models of precipitating cumulus towers. Mon. Wea. Rev., 97 , 471-489.

Simpson, J., and V. Wiggert, 1971: 1968 Florida cumulus seeding experiment: Numerical model results. Mon. Wea. Rev., 99, 87-118.

Simpson, J., and W.L. Woodley, 1971: Seeding cumulus in Florida: New 1970 results. Science, 173, 117-126.

Simpson, J., A. R. Olsen and J. C. Eden, 1975: A Bayesian analysis of a multiplicative treatment effect in weather modification. Technometrics, 17, 161-166.

Simpson, J., 1980: Downdrafts as linkages in dynamic cumulus seeding effects. J. Appl. Meteor., $19,477-487$. 
Simpson, J., N. Westcott, R. Clerman, and R. A. Pielke, 1980: On cumulus mergers. Archiv. Meteor. Geophys. Bioklim., Ser. A (29), 1-40.

Simpson, J., B. R. Morton, M. C. McCumber, and R. S. Penc, 1986: Observations and mechanisms of GATE waterspouts. J. Atmos. Sci., 43, 753-782.

Simpson, J., R. Adler and G. North, 1988: A proposed Tropical Rainfall Measuring Mission (TRMM) satellite. Bull. Amer. Meteor. Soc., 69, 278-295.

Simpson, J., G. Roff, B. R. Morton, K. Labas, G. Dietachmayer, M. McCumber and R. Penc, 1991: A Great Salt Lake waterspout. Mon. Wea. Rev., 119, 2741-2770.

Simpson, J., T. D. Keenan, B. Ferrier, R.H. Simpson and G. J. Holland, 1993: Cumulus Mergers in the Maritime Continent Region. Meteorol. and Atmos. Phys. 51, 73-99.

Simpson, J., C. Kummerow, W.-K Tao and R. F. Adler, 1996: On the Tropical Tainfall Measuring Mission (TRMM). Meteorology and Atmospheric Physics, 60,19-36.

Simpson, J., E. Ritchie, G. J. Holland, J. Halverson and S. Stewart, 1997: Mesoscale interactions in tropical cyclone genesis. Mon. Wea. Rev., 125, 2643-2661.

Simpson, J., J. Halverson, H. Pierce, C. Morales, and T. Iguchi, 1998. Eyeing the Eye: Exciting early stage science results from TRMM. Bull. Amer. Meteor. Soc., 79, 1711.

Simpson, J., C. Kummerow, R. Meneghini, A. Hou, R. F. Adler, G. Huffman, B. Barkstrom, B. Wielicki, S. Goodman, H. Christian, T. Kozu, T. N. Krishnamurti, and B. Ferrier, 2000: The Tropical Rainfall Measuring Mission (TRMM) Progress Report. Earth Observation and Remote Sensing, 4, 71-90.

Tao, W.-K., and J. Simpson, 1989: A further study of cumulus interactions and mergers: Threedimensional simulation with trajectory analyses. J. Atmos. Sci., 46, 2974-3004.

Tao, W.-K, S. Lang, J. Simpson, and R. F. Adler, 1993: Retrieval algorithms for estimating the vertical profiles of latent heat release: Their applications for TRMM. J. Meteor. Soc. Japan, 71, No. 6, 685-700. 
Tao, W.-K., 2001: Goddard Cumulus Ensemble (GCE) model: Application for understanding precipitation processes. Meteor. Monograph., (this issue).

Telford, J. W., and J. Warner, 1964: Fluxes of heat and water vapor in the lower atmosphere derived from aircraft observations. J. Atmos. Sci., 23, 539-548.

Ulanski, S., and M. Garstang, 1978: The role of surface divergence and vorticity in the life cycle of convective rainfall. Part I: Observation and analysis. J. Atmos. Sci., 35, 1063-1069.

Wakimoto, R. M., and J. W. Wilson, 1989: Nonsupercell tornadoes. Mon. Wea. Rev., 117, 11131140.

Wakimoto, R. M., N. A. Atkins, and C. Liu, 1995: Observations of the early evolution of an explosive oceanic cyclone during ERICA IOP5. Part II: Airborne Doppler Analysis of the mesoscale circulation and frontal structure. Mon. Wea. Rev., 123, 1311-1327.

Wang, Y., W.-K. Tao, and J. Simpson, 1996: The impact of ocean surface fluxes on a TOGA COARE convective system. Mon. Wea. Rev., 110, 504-520.

Wang, Y., W.-K. Tao, J. Simpson, and S. Lang, 2001: The sensitivity of tropical squall lines to Surface Fluxes: Cloud resolving model simulations. Q. J. Roy. Meteor. Soc., submitted.

Winston, J. S., 1955: Physical aspects of rapid cyclogenesis in the Gulf of Alaska. Tellus, 7, 481500 .

Woodcock, A. H., and J. Wyman, 1947: Convective motion in air over the sea. Ann. N. Y. Acad. Sci., 48, 749-776.

Zipser, E. J., 1969: The role of organized unsaturated convective downdrafts in the structure and rapid decay of an equatorial disturbance. J. Appl. Meteor., 8, 799-814.

Zipser, E. J., 1977: Mesoscale- and convective-scale downdrafts as distinct components of squallline circulation. Mon. Wea. Rev., 105, 1568-1589. 


\section{Figure Captions}

Figure 1 Vertical profiles of $Q$. (From Riehl and Malkus 1958.)

Figure 2 Model of the mean vertical distribution of $Q$. Mechanisms of upward heat flow in the troposphere, and the limit of the upward penetration of heat gained by the atmosphere the from ground. (From Riehl and Malkus 1958.)

Figure 3 Oliver color overlay of Willis Island radar echoes on a GMS satellite image. The red area represents cloud tops colder than $208 \mathrm{~K}$, while the yellow is $184 \mathrm{~K}$. The radar is not calibrated exactly; the stronger echoes are in lighter blue. The hurricane symbol denotes the pressure and wind vortex center, coincident within analysis uncertainty. The hot tower locations from the lidar are denoted as A-E. As shown in Table 2, D in the forming eyewall tops at $17 \mathrm{~km}$ while the tallest tower $\mathrm{C}$ is in the major rainband in the western MCS. The solid lines are isobars. The $\mathrm{W}$ symbols denote warm core, with $\mathrm{W}_{1} \mathrm{~L}$ apparently west of $\mathrm{W}_{\mathrm{u}}$. W2 is a weaker warm core remaining with the weaker, sheared MCS. Asterisks denote the ten locations of strong electric fields.

Figure 4 Equivalent mountain corresponding to a rectangular-shaped temperature profile. Elevation of mountain $\mathrm{M}(\mathrm{x})$ as a function of $\mathrm{x}$ is shown by the heavy line. The amount by which the island surface temperature exceeds that of the water determines the effective height of the equivalent mountain. The distance of exponential decay of the mountain, in this example is 0.3 times the island width. This would represent a distance of $3 \mathrm{~km}$ if $2 \mathrm{D}$ were $10 \mathrm{~km}, \mathrm{U}=2 \mathrm{~m} \mathrm{~s}^{-1}$ and $\mathrm{K}=2.6 \times 10^{5} \mathrm{~cm}^{2} \mathrm{~s}^{-1}$. For a 2 degrees $\mathrm{C}$ temperature perturbation of the island temperature, the maximum height reached by the mountain would be $667 \mathrm{~m}$ (adapted from Stern and Malkus 1953b).

Figure 5 Equivalent mountain for Nantucket Island on 14 August 1950 (Case 4 studied by Malkus and Bunker 1952). T degrees ( $\mathrm{x}$ ) was the observed temperature profile along the island surface. The mountain function $M(x)$ is shown to have a similar shape to $\mathrm{T}$ degrees $(\mathrm{x})$. The horizontal extent of the island is shown by the hatched region (adapted from Stern and Malkus 1953b).

Figure 6 Seeding effect versus seedability for the 23 clouds obtained during the randomized Caribbean cloud seeding experimentation in 1965. The seeded clouds are in circles and the control clouds are in boxes. See the text for details. 
Figure 7 Vertical structure of the air along the trajectory. Horizontal distance given in $\mathrm{km}$ downstream of entrance end. Vertical coordinate on the right in $\mathrm{mb}$, and on the left in $\mathrm{km}$ (approximate). The heavy lines separate the layers. The lines with arrows are trajectories while the lighter solid lines are potential temperature isopleths labeled in degrees absolute. Trade cumulus clouds are entered schematically. To the right is the profile of wind speed (along the section) at the upstream end and to the left is the wind speed profile at the downstream end. Wind speeds are in $\mathrm{m} \mathrm{s}^{-1}$ (adapted from Malkus 1956).

Figure 8 Subdivision of the Trade Wind boundary layer, based on Malkus (1958b).

Figure 9 Schematic of roll circulations and their relationship to cloud streets. The roll circulations (broad arrows) draw buoyant elements (outlined with stippling) into their upwelling regions and enable the buoyant elements to penetrate higher than otherwise, leading to cloud streets.

Figure 10 Schematic illustration relating downdraft interaction to bridging and merger in the case of moderate shear opposite to the wind direction through most of the vertical extent of the cloud layer. The newer cumulonimbus on the right has predominately upward motion and moves faster than the ambient wind. The older cumulonimbus on the left has predominately downward motion and moves slower than the ambient wind so that the clouds move and propagate toward each other. The interaction of downdrafts enhances bridge development (adapted from Simpson et al. 1980).

Figure 11 Schematic illustration (not to scale) of cumulus-outflow interactions in relation to invigorated cumulus over a developing parent vortex. The shaded region approximately outlines the vortex core of one of the vortex pair organized by the model cloud F on Day 186. The circle at the surface within the core is the sea surface dark spot; the dashed vertical lines show where the condensation funnel will appear as the central pressure drops. The gust front within and beneath cloud $\mathrm{F}$ is not shown on this diagram.

Figure 12 (Upper left) GMS IR image at 0532 UTC 10 December 1997. The coldest IR temperature (at this $4 \mathrm{~km}$ resolution) is $179 \mathrm{~K}$.. (Upper right) TRMM precipitation radar (PR) image at 0535 UTC superimposed on the GMS image. Note the eye within 
the coldest portion of the GMS image, which showed no eye. (Lower left) TRMM Microwave Imager (TMI) 85-Ghz channel superimposed on the GMS image. Wider swath on TMI shows the cloud pattern of a nearly mature tropical cyclone. (Lower right) Cross-section of TRMM PR from A to B shown in the upper-right PR image. 


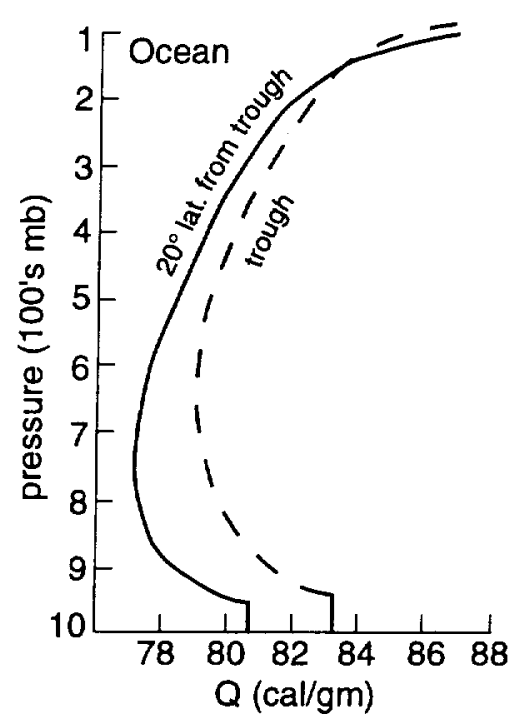

Fig. 1 


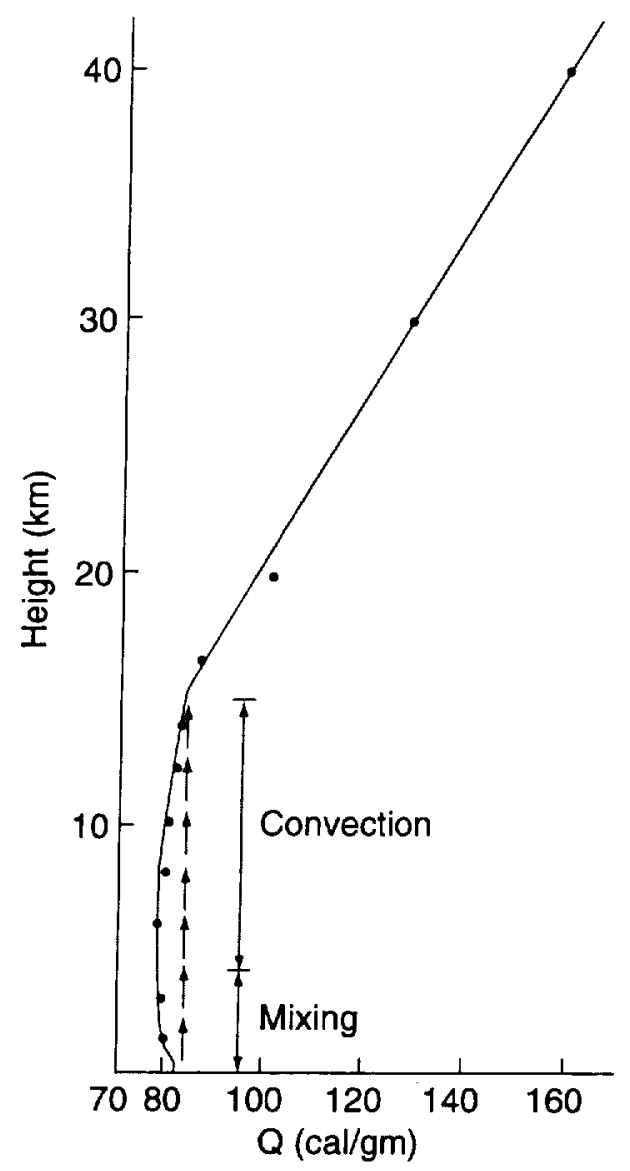

Fig. 2 


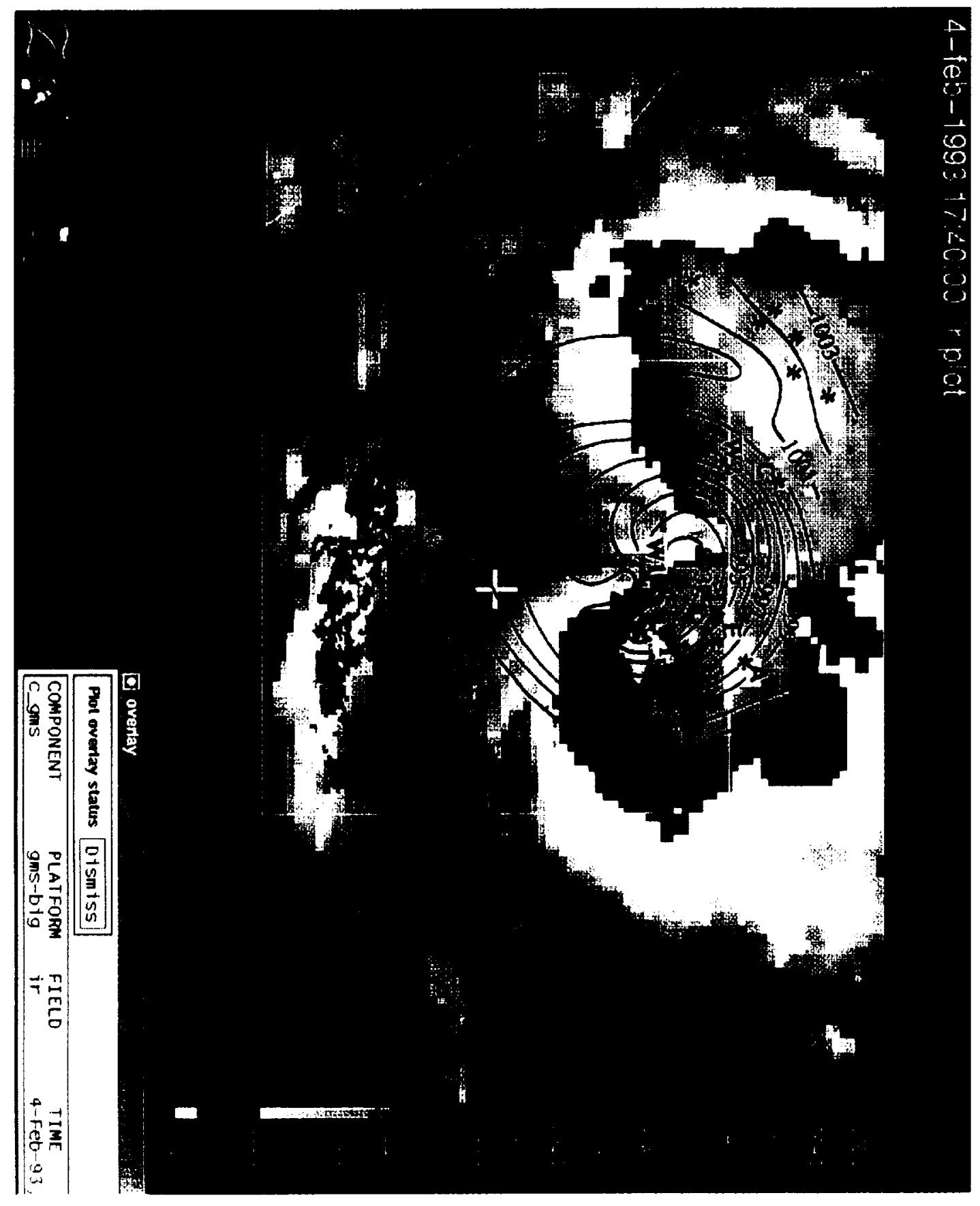

ปุด 


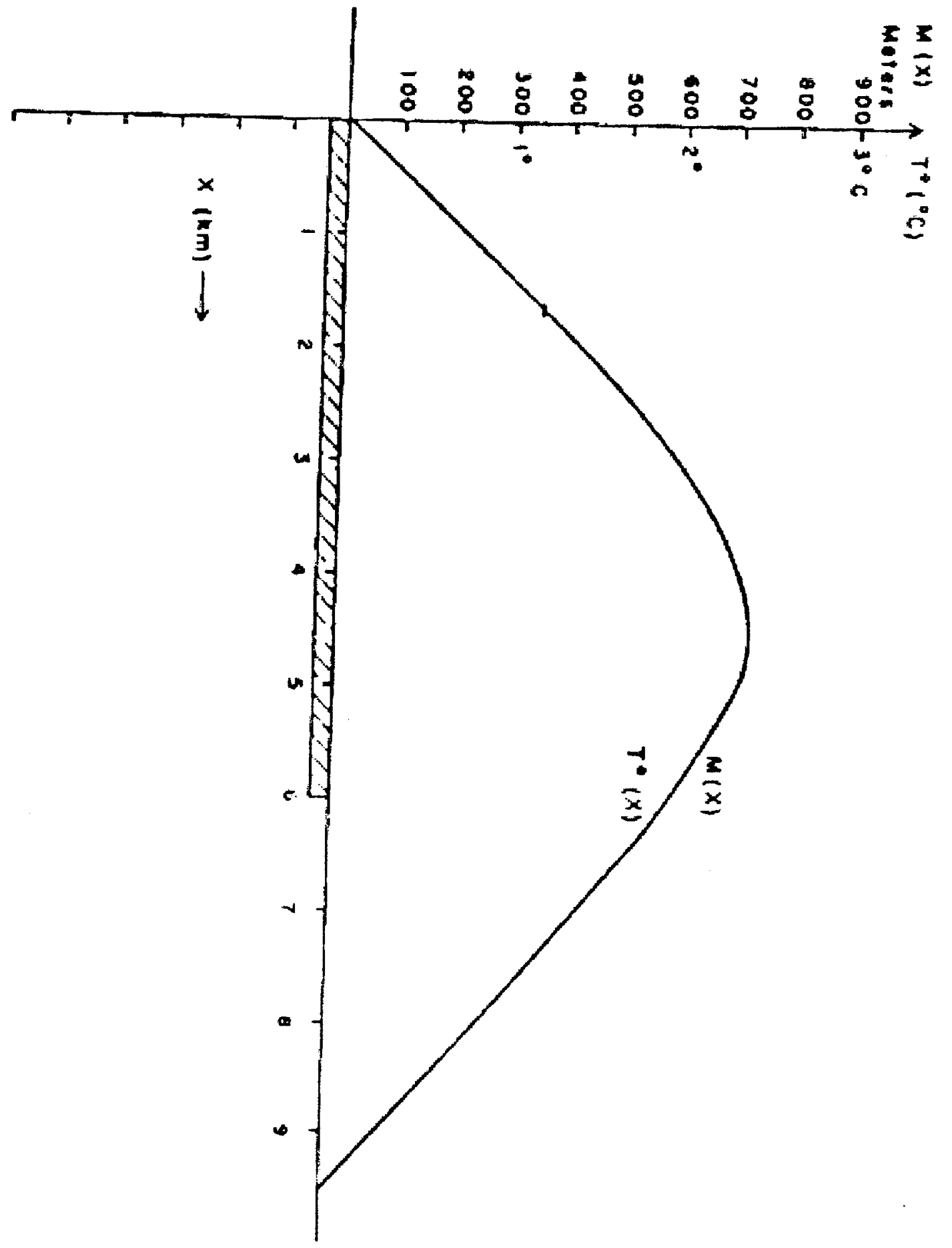

$\underset{10}{11}$ 


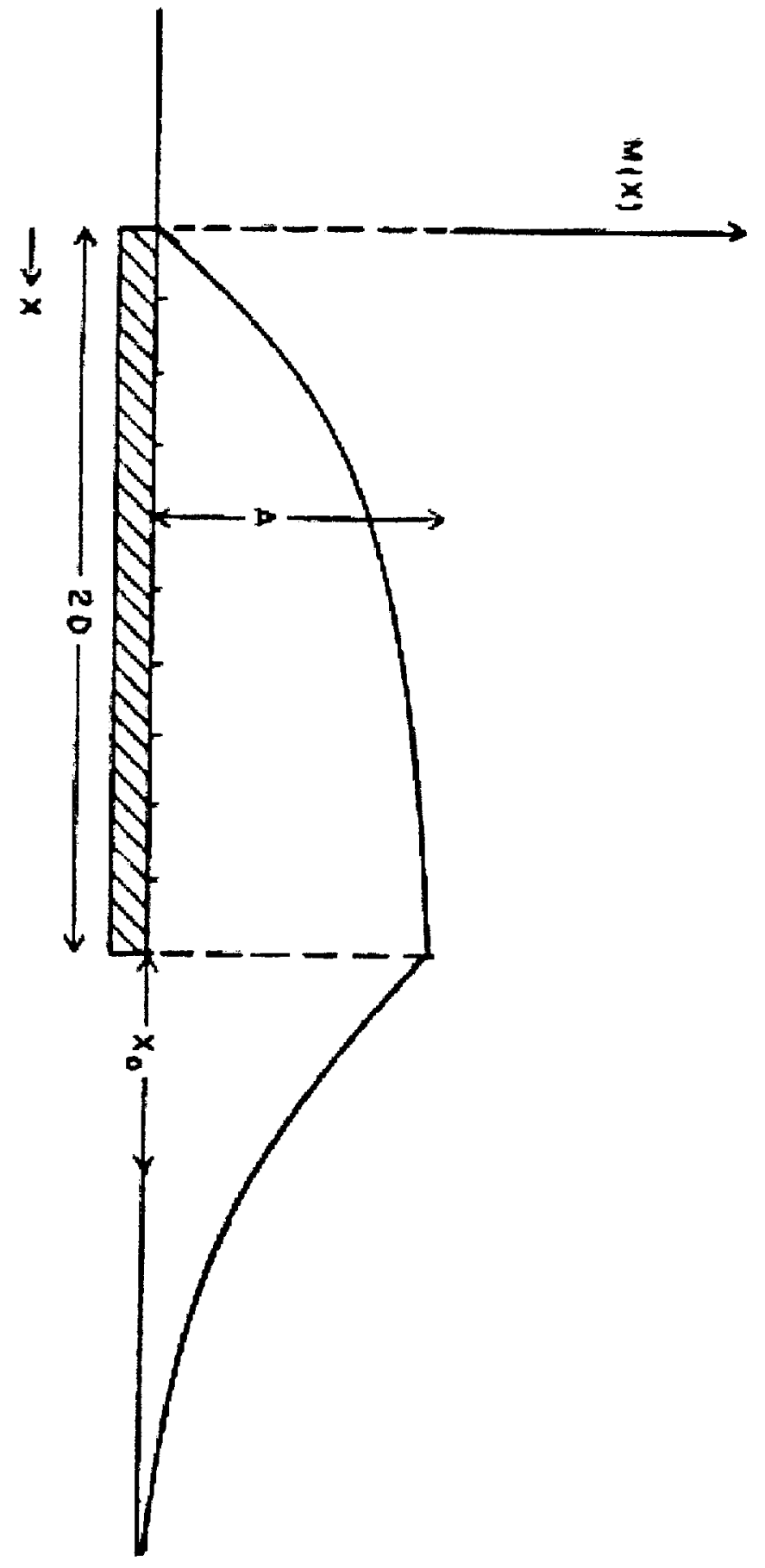

11
0
0 


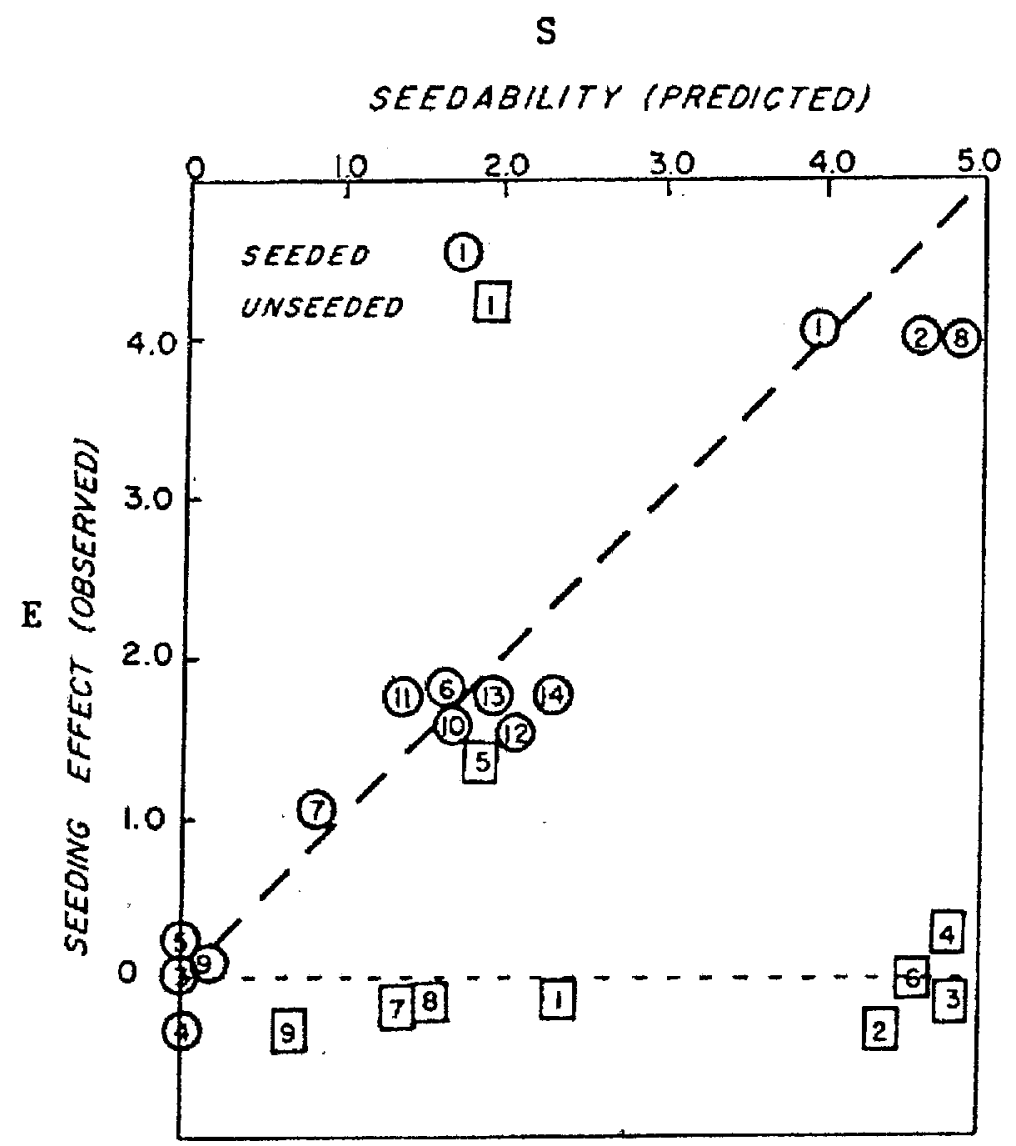

Fig. 6 


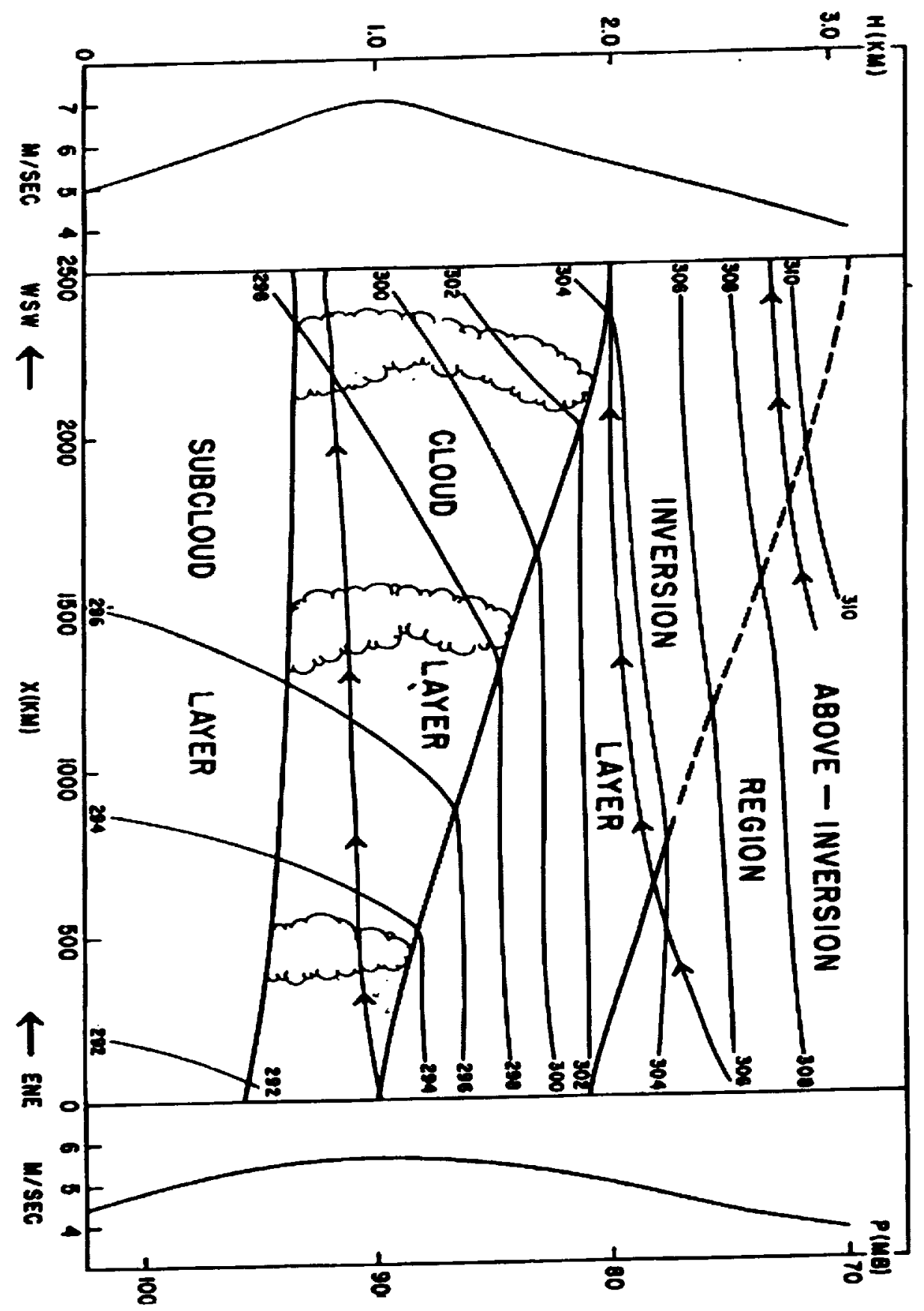

: 


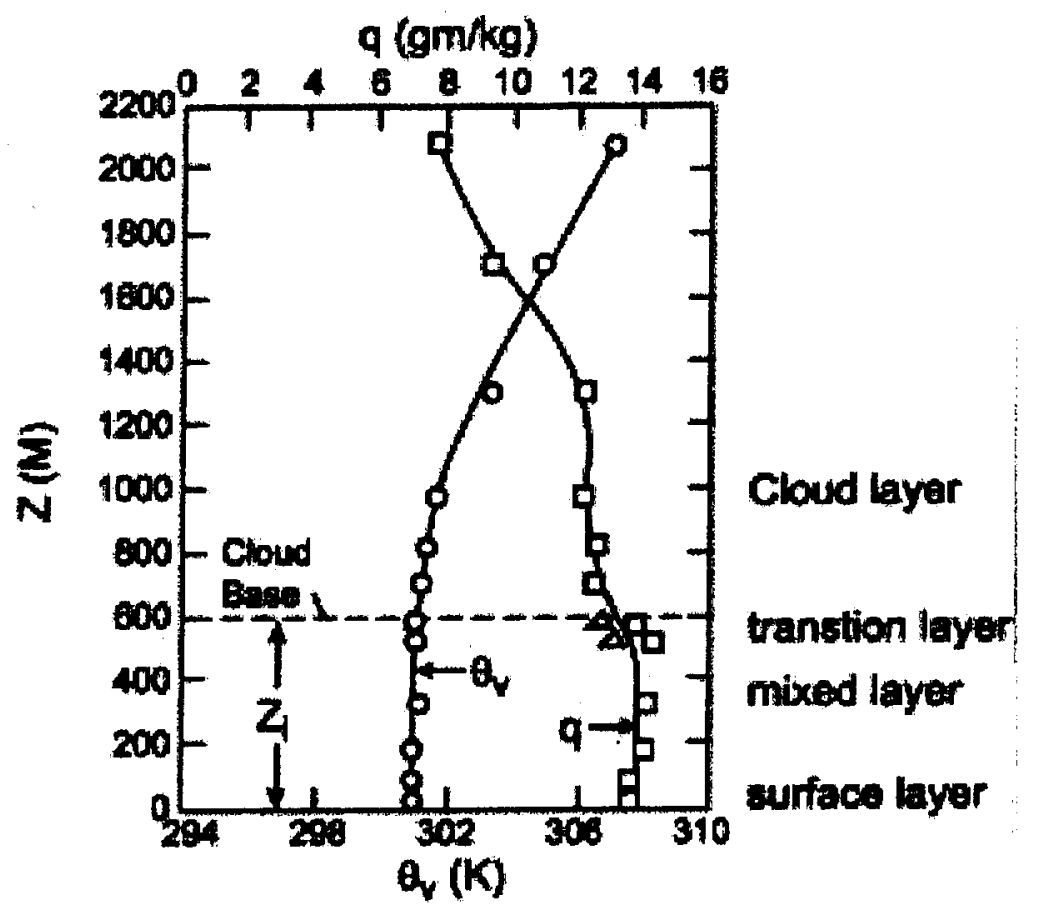

Lin $Q$ 


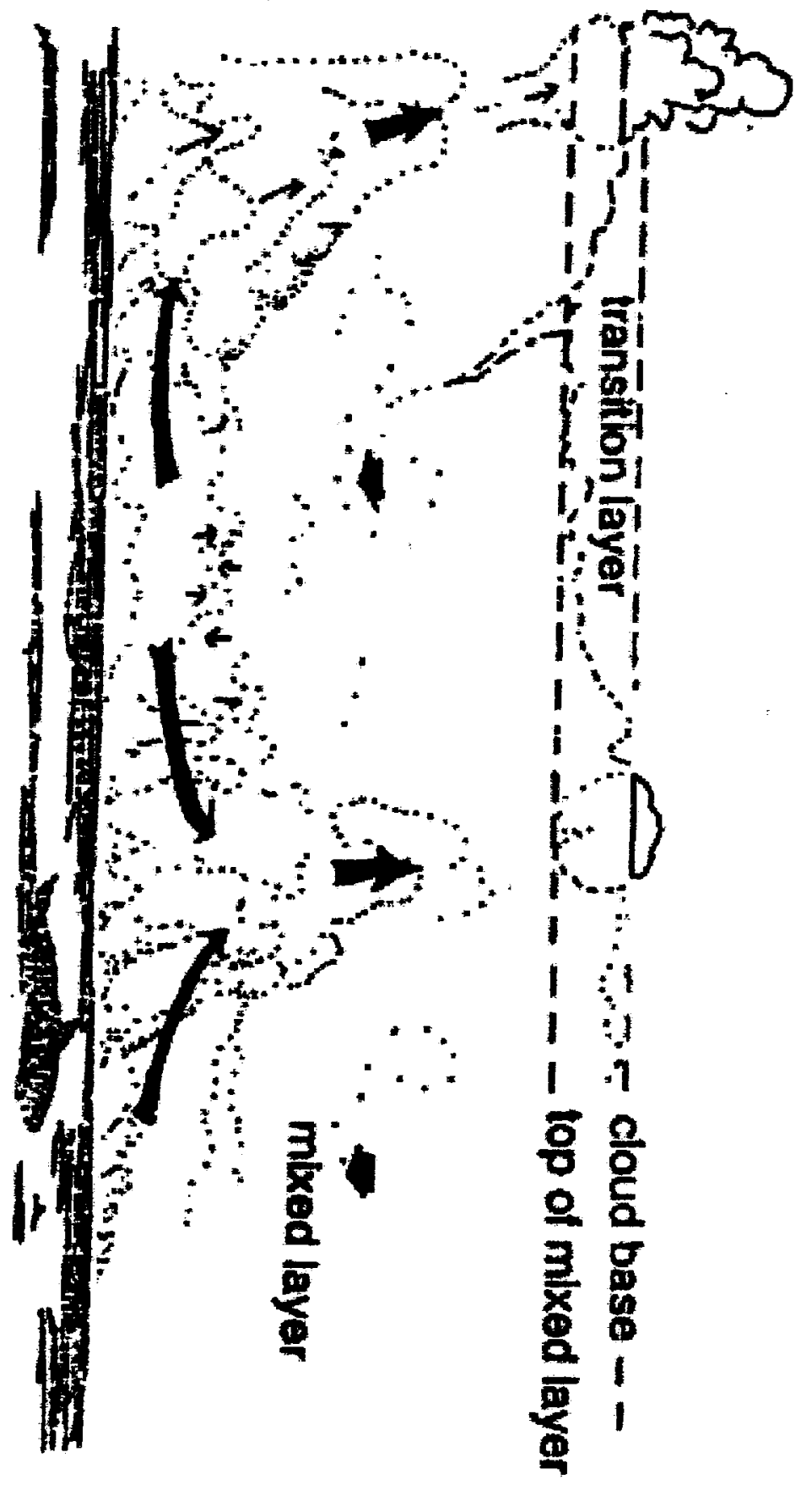

Ṭִ 


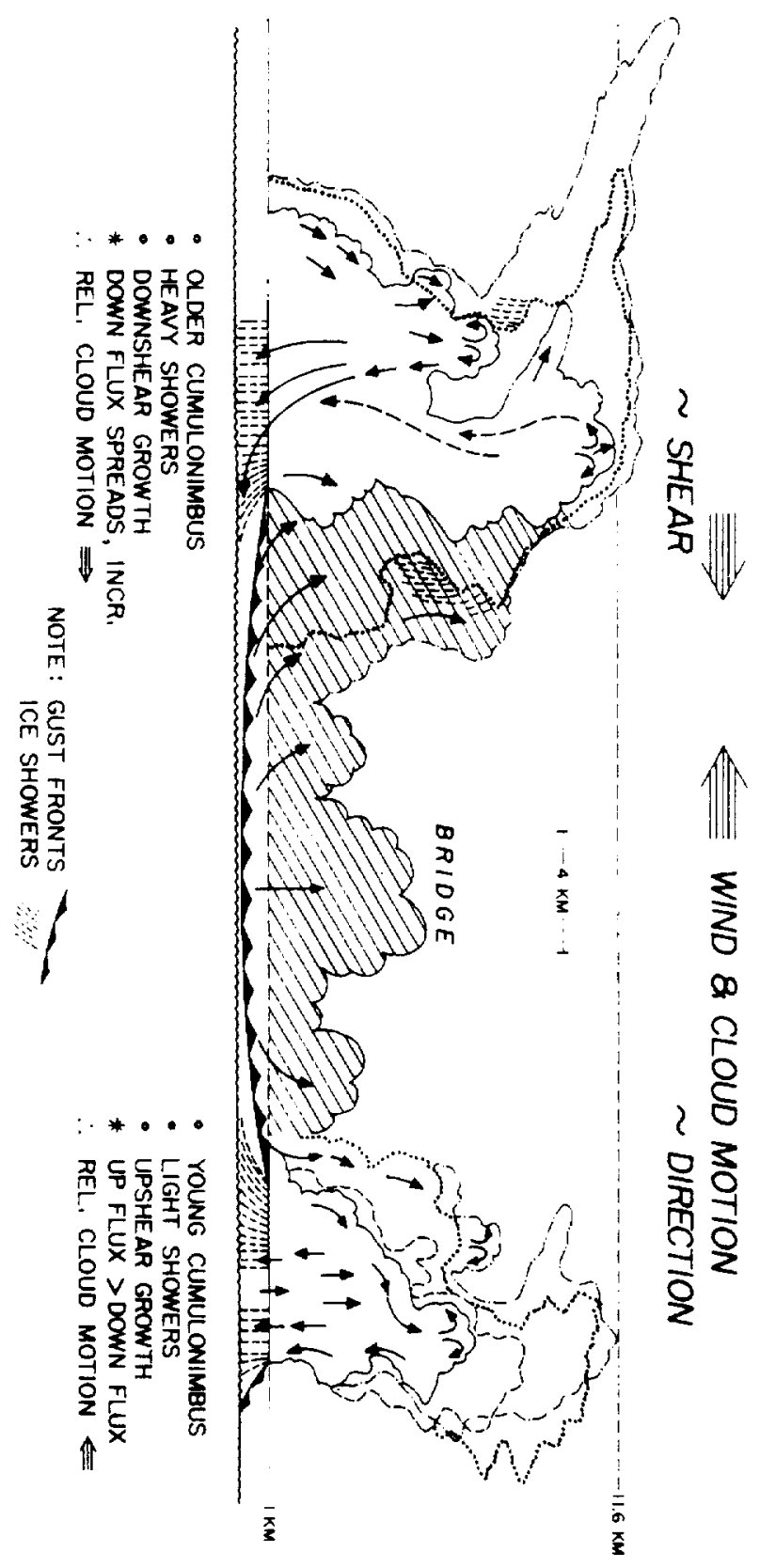

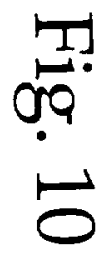




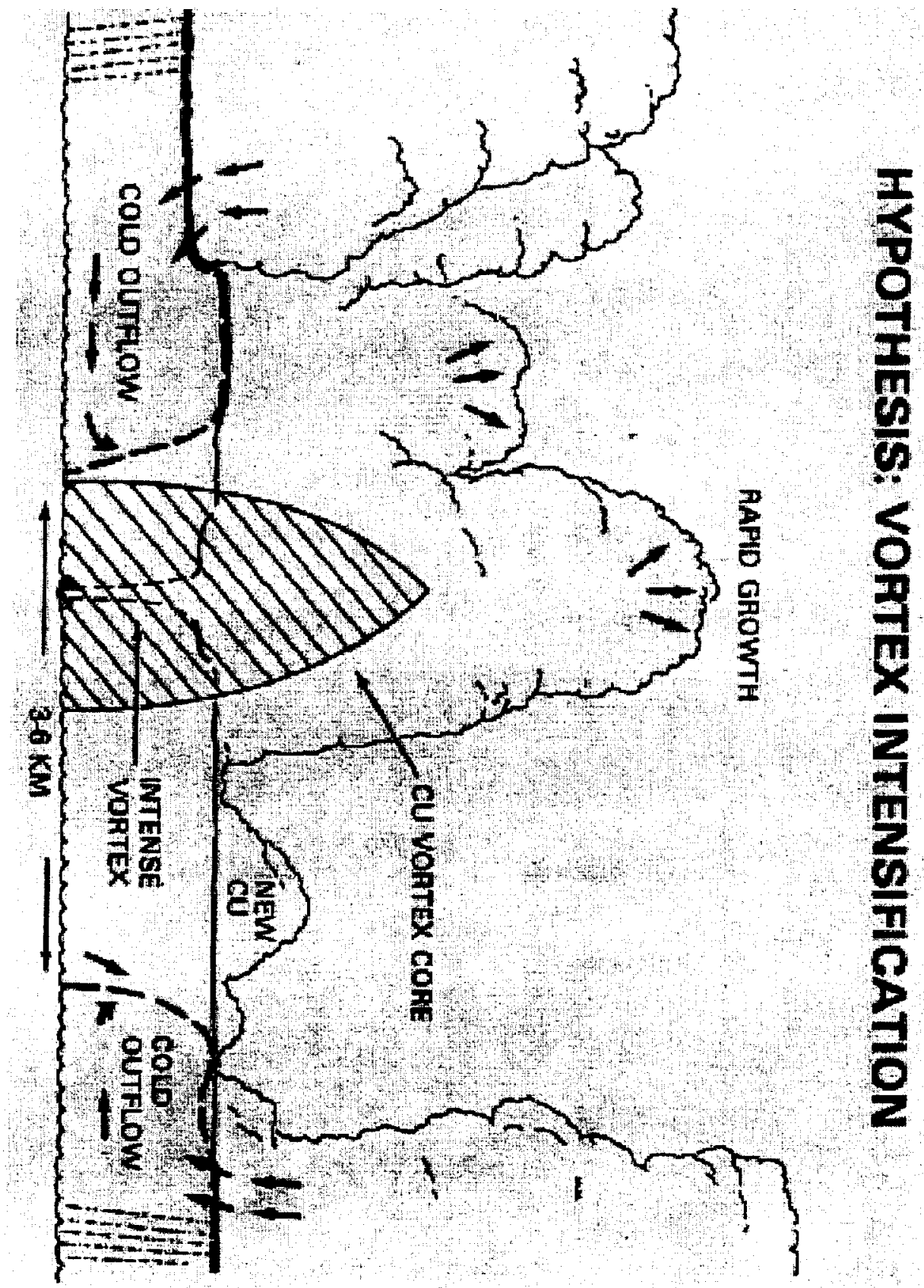

T. 


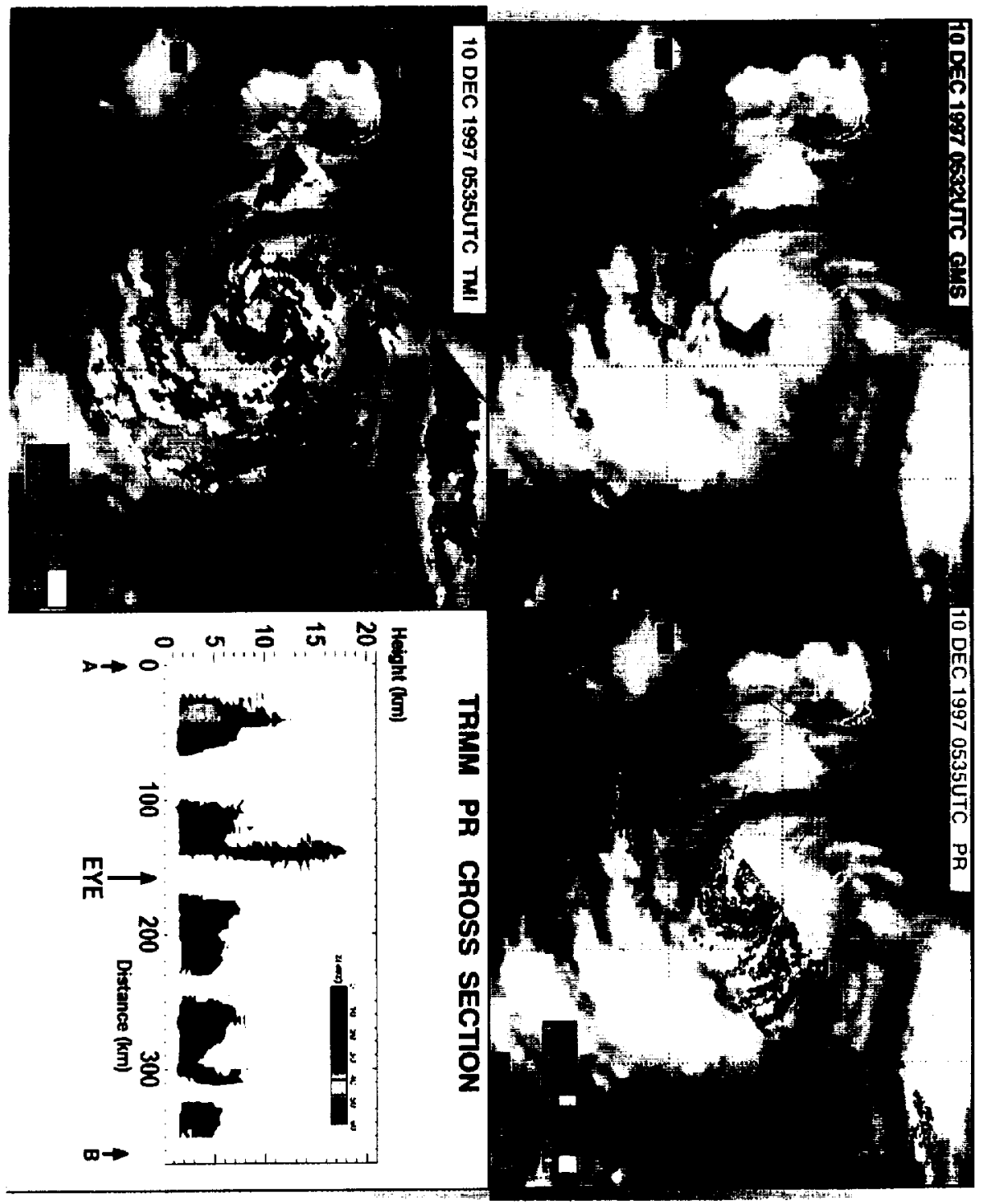

Tִ

$\vec{N}$ 